\title{
Seizure prediction — ready for a new era
}

Levin Kuhlmann $^{1,2,3}$, Klaus Lehnertz ${ }^{4,5 *}$, Mark P. Richardson ${ }^{6}$, Björn Schelter $^{7}$, Hitten P. Zaveri ${ }^{8}$

${ }^{1}$ Centre for Human Psychopharmacology, Swinburne University of Technology, Hawthorne, VIC, Australia

${ }^{2}$ Department of Medicine - St. Vincent's, The University of Melbourne, Parkville, VIC, Australia

${ }^{3}$ Department of Biomedical Engineering, The University of Melbourne, Parkville, VIC, Australia

${ }^{4}$ Department of Epileptology, University of Bonn, Bonn, Germany

${ }^{5}$ Interdisciplinary Center for Complex Systems, University of Bonn, Bonn, Germany

${ }^{6}$ Institute of Psychiatry, Psychology and Neuroscience, King's College London, London, UK

${ }^{7}$ Institute for Complex Systems and Mathematical Biology, University of Aberdeen, Aberdeen, UK

${ }^{8}$ Department of Neurology, Yale University, New Haven, CT, USA

*e-mail: Klaus.Lehnertz@ukb.uni-bonn.de

\begin{abstract}
Epilepsy is a common disorder characterized by recurrent seizures. An overwhelming majority of people with epilepsy regard the unpredictability of seizures as a major issue. More than 30 years of international effort has been devoted to the prediction of seizures, aiming to remove the burden of unpredictability and couple novel, time-specific treatment to seizure prediction technology. A highly-influential review published in 2007 concluded that insufficient evidence indicated that seizures could be predicted. Since then, several advances have been made, including successful prospective seizure prediction using intracranial electroencephalography (EEG) in a small number of people in a trial of a real-time seizure prediction device. In this Review, we examine advances in the field, including EEG databases, seizure prediction competitions, the prospective trial, and advances in our understanding of the mechanisms of seizures. We argue that these advances, together with statistical evaluations, set the stage for a resurgence in efforts towards the development of seizure prediction methodologies. We propose new avenues of investigation involving a synergy between mechanisms, models, data, devices and algorithms and refine the existing guidelines for development of seizure prediction technology to instigate development of a solution that removes the burden of the unpredictability of seizures.
\end{abstract}

\section{[H1] Introduction}

The prevalence of epilepsy is almost $1 \%$ worldwide ${ }^{1}$, and in approximately $30 \%$ of people with epilepsy, the condition is intractable to anti-epileptic drugs ${ }^{2}$. Medically intractable epilepsy is associated with adverse outcomes, including serious comorbidities, injury and death ${ }^{3}$. Central to the burden of intractable epilepsy is the unpredictability of seizures ${ }^{4,5}$, which is a major detriment to quality of life ${ }^{6,7}$. The ability to accurately predict a seizure minutes before onset would enable patients to take precautions against injury and would open the door to novel timely treatment to pre-empt or control the impending seizure.

The field of seizure prediction was established in the 1980s, but after $>20$ years, a comprehensive review published in $2007^{8}$ concluded that "the current literature allows no definite conclusion as to whether seizures are predictable by prospective algorithms". Nevertheless, in the past decade, several innovations have driven the field forward (Fig. 1), including: recognition that potential 
predictors must be robust and that performance evaluation of seizure prediction algorithms must be standardized; the compiling of extensive databases of long-term electroencephalography (EEG) recordings; establishment of international seizure prediction competitions; and a prospective trial of a seizure prediction device that provided convincing evidence that prediction of seizures is possible $^{9}$. In addition, ongoing improvements in our understanding of the mechanisms of seizure generation (ictogenesis) have been important; improved understanding means that the mechanisms of transition to seizure or the physiological factors that make transition to seizure more likely can be taken into account in seizure prediction research.

In this Review, we first outline the basis of seizure prediction algorithms before discussing the developments from the past decade that provide impetus for future development of the seizure prediction field and for larger scale clinical trials of seizure prediction devices. On the assumption that seizure prediction will progress from a research challenge to clinical reality implemented with devices and integrated algorithms that could be coupled to time-specific treatments, we argue that an approach that is compatible with standards and regulations for medical devices and medical treatments is needed. We also propose an extension of the previous guidelines ${ }^{8}$ for the interpretation of seizure prediction studies in the light of new developments, critically assess the findings of recent studies, and suggest future work. We argue that improved understanding of the mechanisms of transition from normal brain activity to seizure has the potential to improve seizure prediction, and that such improvements will better define and enable leveraging of the synergy between mechanisms, models, data, devices and algorithms.

\section{[H1] Seizure prediction algorithms}

Seizure prediction algorithms typically follow the same basic scheme (Fig. 2). Continuously acquired physiological signals, most commonly intracranial EEG, are analysed with advanced timeseries analysis methods to identify predictive characteristics (Box 1). These temporally resolved characteristics are in turn used in decision algorithms to trigger an alarm that warns the patient or their carer, or, in a closed-loop system, trigger delivery of pharmacological or non-pharmacological control of seizures.

Ideally, a seizure prediction algorithm would forecast seizure onset with sufficient warning for preparation or intervention, sufficient precision to minimize interruption to an individual's life, and with minimal false alarms and unpredicted seizures. Predictions made during the (assumed) preictal period are considered true predictions, and those made outside the pre-ictal period are considered false predictions (Fig. 2c). Although the approach outlined is widely used, algorithms need further improvement by drawing on knowledge of seizure mechanisms, multimodal imaging and neurophysiology, computational modelling and control theory ${ }^{10}$.

Several approaches and guidelines are used to evaluate seizure prediction algorithms ${ }^{8}$. These approaches involve receiver operating characteristic (ROC) curves that assess the true positive rate against the false positive rate during windows of pre-ictal or inter-ictal data. Approaches that help determine the clinical utility of an algorithm involve prospective or pseudo-prospective evaluation of sensitivity and measurement of time spent under a false warning ${ }^{11,12}$. Overall algorithm performance can be quantified and ranked by the area under the curve (AUC) for either true positive rate versus false positive rate or for sensitivity versus portion of time in false warning (Fig. 3). Ranking of the AUC only becomes meaningful if complemented by statistical evaluation based on random or surrogate predictors.

\section{[H1] Developments and innovations}

\section{[H2] Need for robust predictors}

Optimism for seizure prediction was high in the late $20^{\text {th }}$ and early $21^{\text {st }}$ centuries after many algorithms seemed to enable seizure prediction. However, the landmark review in $2007^{8}$ pointed out that fundamentally flawed methods had been used to demonstrate above-chance performance of seizure prediction algorithms. Subsequent rigorous tests of seizure prediction showed no evidence of above-chance prediction ${ }^{8}$. This key fault of historic literature continues to pervade the field. 
No predictive characteristic or pre-seizure biomarker (Box 1) that is universal among people with epilepsy and that can forecast the exact time of an individual's next seizure has been identified. ${ }^{9,13-}$

${ }^{18}$. Typically, a time window in which a seizure is likely to occur is determined. With a longer time window, the prediction is more likely to be correct, even if the so-called predictor has no predictive value. This observation poses the question of how we can determine whether potential seizure predictors do actually predict seizures rather than merely identify random fluctuations in physiological signals that have no association with seizures. This key challenge in seizure prediction - which is often neglected - requires standardized rigorous statistical evaluation of predictive performance (guidelines have been published elsewhere ${ }^{8}$ ) because seizure events are relatively rare and seizure-free intervals are often long.

A simple approach to such analysis is to compare the performance of a prediction algorithm to that of a random predictor ${ }^{11,19}$ that generates predictions at random times at the same rate as that of the algorithm. If required, a random predictor can be adjusted to account for a person's diurnal variation in seizure distribution or other characteristics ${ }^{15}$. More advanced approaches make use of Monte-Carlo simulations (and other such simulations) to generate predictor surrogates, such as the random shifting of seizure times to generate false seizure times ${ }^{20-22}$ The performance of the prediction algorithm is then statistically compared to performance of these predictor surrogates. Comparison with a random predictor is computationally the most efficient form of statistical evaluation of performance of a prediction algorithm. Surrogate-based approaches are more timeintensive, but offer greater confidence in determining whether or not an algorithm performs better than chance and can account for the non-random occurrence of seizures. Awareness of the importance of statistical evaluation of seizure prediction algorithms is critical for understanding the value of the results of the seizure prediction studies.

\section{[H2] Databases and associated studies}

The development of seizure prediction algorithms is critically dependent on the availability of continuous, annotated, long-term data. Such data sets enable researchers to generate hypotheses and statistically validate prospective algorithms. Historically, few investigators have had access to comprehensive data ${ }^{23}$. Recognition of this limitation prompted substantial international efforts during the past decade to provide universal access to multi-channel, multi-day EEG data that include sleep, wakefulness, and activities of daily life to provide a pseudo-realistic test bed.

Two major publicly available databases have resulted from this unprecedented effort. One is the EPILEPSIAE < www.epilepsiae.eu> database ${ }^{24,25}$, which superseded the smaller FSPEEG database $^{12}$ that comprised non-continuous data sets. The other is the ieeg.org database ${ }^{26,27}$, which provides the infrastructure to remotely process data within the database. In addition, individual research groups have created databases and long-term data sets ${ }^{9}$ that include data of up to 3 years' duration, albeit for only a few people with epilepsy. The new Epilepsy Ecosystem $<$ Epilepsyecosystem.org $>^{13}$ database offers access to these long-term data sets.

Data from these databases have formed the basis of many seizure prediction studies, and have an ongoing effect on retrospective evaluation of seizure prediction algorithms. Several seizure prediction algorithms have been developed on the basis of these databases since the comprehensive review of seizure prediction in $2007^{8}$ (Supplementary tables 1 and 2), though their adherence to the guidelines in that review varies (Supplementary box 1). When considering these studies, it is important to note that the results are sensitive to the kind of data used: some studies include data from seizure periods (ictal), seizure-free intervals (inter-ictal), the pre-seizure period (pre-ictal) and post-seizure (post-ictal) period, whereas others focus on non-continuous selected pre-seizure and inter-ictal data. The specificity of the latter studies cannot be accurately assessed owing to selection bias in the inter-ictal data.

Many algorithms have been applied to data from the seizure prediction databases. Studies in which algorithms have been applied to subsets of data, recordings that are too short or noncontinuous data have generally indicated better sensitivity of algorithms, lower false positive rates and less time in false warning periods than studies in which larger data sets have been used. This observation can probably be attributed to in-sample testing and selection bias in studies in which 
non-continuous data have been used, a limited number of seizures among the data and a limited amount of data from inter-ictal periods. Algorithms that have been assessed with small data sets will, therefore, have to be re-evaluated with larger datasets to assess their true contribution to seizure prediction.

The principal finding from studies of these databases is that individual-specific, above-chance seizure prediction seems to be achievable. Prior to the creation of larger databases, research involved very limited amounts of data and many conflicting claims were made regarding seizure prediction performance ${ }^{8}$. Prediction times in relation to the seizure and the duration of an assumed pre-seizure period vary widely across studies and individuals, suggesting that seizure prediction algorithms should be individual-specific and/or specific to the intervention that would be used upon prediction. The findings also suggest that neurophysiological understanding of the pre-seizure state must be improved to determine whether universal mechanisms lead to the variety of observed pre-seizure states.

Despite being well-annotated, databases were not designed to provide deep insights into seizuregenerating mechanisms. Nevertheless, databases can provide indirect insights into potential mechanisms. For example, seizure prediction on the basis of long-term data can be sensitive to the different phases of the sleep-wake cycle ${ }^{15,28}$. Whether the temporal variability of other predictive factors, such as hormonal cycles, affect the probability of seizure occurrence and the prediction of seizures remains to be investigated ${ }^{29}$. Such factors do influence continuous EEG data collected over extended periods from humans going about their daily lives ${ }^{9,29-31}$, and taking account of these factors is expected to improve seizure prediction in some individuals.

The nature of databases means that they can only be used for hypothesis generation because the data have already been collected, which renders a truly prospective analysis impossible. The same data in the databases are typically used repeatedly with different algorithms to assess seizure prediction performance, which reduces the reliability of conclusions drawn. Findings based on databases do not enable definite conclusion about seizure prediction to be drawn, but can suggest algorithms that are likely to perform well in prospective clinical trials by ruling out those that underperform even with retrospective data.

\section{[H2] Seizure prediction competitions}

Databases have enabled some standardization of data to be tested, and rigorous statistical criteria have standardized the assessment of seizure prediction results, but considerable leeway remains in the comparison of algorithms with each other. During the past decade, international seizure prediction competitions have driven the field forward by standardizing the comparision of different algorithms on the basis of their performance with a common set of data.

Seizure prediction competitions emerged from the International Workshops on Seizure Prediction (IWSP, now named the International Conference for Technology and Analysis of Seizures) ${ }^{10,23,32-37}$. The first two competitions in 2007 and 2009 (Fig. 1), conducted in conjunction with IWSP3 and IWSP4, involved continuous intracranial EEG data from three people with epilepsy ${ }^{38}$. Entrants were provided with a training set, and a test set was used to assess the algorithms entered into the competition. Of fewer than 10 entrants, none achieved above-chance prediction performance.

In 2014 and 2016, large-scale international seizure prediction competitions were run on a standard data science contest portal ${ }^{13,39}$. The 2014 competition (American Epilepsy Society Seizure Prediction Challenge <www.kaggle.com/c/seizure-prediction $>$ ) involved a combination of short-term human intracranial EEG data (with 942 seizures recorded over $>500$ days) and long-term intracranial EEG data in dogs (348 seizures recorded over 1,500 days $)^{39,40}$ All entrants were provided the same set of discontinuous 10-minute segments of inter-ictal and pre-seizure data for training their algorithm; additional, unlabelled 10-minute segments of EEG recordings from the same people with epilepsy were then provided for testing their algorithm. Although less ideal than use of continuous data ${ }^{8}$, this approach was more tractable for the entrants and the evaluators, given the large amounts of data involved. The 2016 contest (Melbourne University AES/MathWorks/NIH Seizure Prediction < https://www.kaggle.com/c/melbourne-university-seizure-prediction) involved long-term intracranial EEG data (1,139 seizures recorded over 1,326 days) from three people with epilepsy whose seizures were hard to predict with existing approaches ${ }^{9,13}$. The structure of the competition was 
similar to the one run in 2014. Combined, the 2014 and 2016 contests had more than 1,200 participants and included many who had not previously been active in the field of seizure prediction.

Evaluation of seizure prediction algorithms in both contests involved use of the area under the curve (AUC) metric (Fig. 3). The top performing entry in the 2014 contest was based on a combination of various machine learning algorithms, and produced an AUC value of 0.84 out of $1^{39}$. Performance for this algorithm dropped by only $8 \%$ when applied to a much larger dataset. The top algorithm from the 2016 contest produced a similar AUC value of 0.81 for long-term human data ${ }^{13}$.

Although competitions are highly compelling and enable standardized comparison of algorithms, they also raise new challenges in the assessment of seizure prediction algorithms. A large number of algorithms were assessed, and some might have performed well by chance. Without appropriate statistical correction for multiple testing, unwarranted positive conclusions about a seizure prediction algorithm are possible. A statistical comparison test of the methods, including correction for multiple comparisons, was performed for the 2016 competition and indicated that no one algorithm is best for a given person, rather sets of algorithms work better than other sets of algorithms for a given person ${ }^{13}$.

\section{[H2] A prospective seizure prediction system}

To date, only one clinical trial of a fully-functioning seizure prediction system, which the investigators who developed it described as a seizure advisory system ${ }^{9}$, has been conducted. The system consisted of intracranial implanted electrodes connected by subdermal wires to a subdermal telemetry unit implanted in the chest, which wirelessly transmitted the EEG data to a hand-held unit (Fig. 2b). This unit processed the data in real time using an individualized algorithm, and displayed warning lights to the person depending on whether the likelihood of a seizure was high, moderate or low. The study consisted of two phases: in the first phase, the device was implanted and data was recorded continuously until the required number of seizures had occurred. These data were analysed offline, to identify an individual-specific algorithm. Fifteen people with epilepsy received an implant, and 11 completed the first phase; an algorithm was developed for nine people who experienced sufficient seizures to enable statistical assessment of algorithms. These nine individuals then entered the second phase, in which the developed algorithm was run prospectively in real time for 4 months.

Prospective seizure prediction was above chance for nine people and was excellent for three: prospective seizure prediction sensitivities (the percentage of seizures correctly predicted) were $86 \%, 100 \%$, and $100 \%$ for thirteen, three and three seizures, respectively, during the evaluation period. The percentage of time for which these three individuals were under a warning of high seizure likelihood was $27 \%, 31 \%$ and $3 \%$, respectively. In the other six people, sensitivity was $54-$ $71 \%$, and the percentage of time under high seizure likelihood warning was $15-41 \%$.

This trial was a landmark study in the field of seizure prediction, and remains the only successful demonstration of prospective human seizure prediction to date 9 . Another major aspect that contributes to the importance of the study is that it involved human intracranial EEG recordings of up to 3 years per person. Standard ambulatory intracranial recordings in hospital continue for a maximum of 4 weeks and do not necessarily include an adequate number of seizures to enable statistically reliable assessment of seizure prediction ${ }^{8}$. Furthermore, this study demonstrated that such long-term recordings are possible, that seizure prediction algorithms seem to work best when developed in a patient-specific manner, that people with epilepsy are willing to volunteer for such studies, and that research ethics committees see the benefits of these trials. Thus, the door has been opened for more long-term prospective trials.

The field of seizure prediction has been encouraged by this first demonstration of feasibility of seizure prediction. The earliest studies of seizure prediction were restricted by limited data sets and computational power. Computing power has evolved, but the costs and practical challenges of acquiring long-term data sets that contain adequate numbers of seizures for reliable statistical evaluation remain considerable. The earlier studies or studies with limited data sets should not, 
therefore, be considered as failed attempts, rather as having laid the groundwork that made completion of a prospective clinical trial of seizure prediction possible.

Further work is needed to understand why seizure prediction performance was low for six of the nine assessable participants in the trial so that seizure prediction could be improved for these people $^{13}$. The algorithms derived from such an analysis could be applicable to other people with epilepsy. More knowledge about the seizures of people for whom the prediction algorithms performed poorly could help to better understand and better classify epilepsy. In addition, more knowledge about the seizures that were difficult to predict or were unpredictable is important, as this knowledge could lead to improvements in seizure prediction. Indeed, analysis of seizure statistics (such as seizure duration and frequency) from the trial data set, ${ }^{9,15,31,41,42}$ has identified factors that were related to poor seizure prediction; these factors included a high frequency of seizures $^{9}$, long-term temporal variations in seizure frequency ${ }^{30}$, or multi-modal distributions of seizure duration and inter-ictal intervals ${ }^{31}$.

The analysis also identified factors associated with good seizure prediction, including an increase in the frequency of EEG spikes before seizures ${ }^{41}$. This observation suggests that characterization of an individual's seizure and spike statistics could improve prediction performance, and that more than one predictive factor is required for people with multi-modal distributions of seizure duration. However, contradictory findings on the role of EEG spikes and their temporal relationship to seizures add uncertainty. This area remains under investigation ${ }^{43-53}$. An analysis of long-term recordings published in 2018 has produced results that are consistent with those of the trial ${ }^{41}$ and indicate that seizures occur preferentially during the rising phase of multi-day rhythms of inter-ictal epileptiform activity ${ }^{54}$. Analysis of the trial data set also indicates that incorporating factors such as the time of day is another potential avenue for improving prediction ${ }^{13,15}$.

\section{[H1] Emerging science for seizure prediction}

Many existing studies of seizure prediction have been performed with little consideration of the mechanisms that underlie the transition from apparently normal brain activity to seizure. Most studies have also been performed with EEG, a modality that does not lend itself to determination of underlying mechanisms. Further, analysis with techniques such as machine learning does not readily reveal which physiological aspects underlie the predictive characteristics of the EEG. These approaches, though commendable for their pragmatism, have resulted in a limited understanding of the mechanistic underpinnings of the pre-ictal state. An understanding of the underlying mechanisms will result in a better understanding of ictogenesis, better translation of the information collected into methods to detect, predict and control seizures, and eventually a better understanding of what a seizure is ${ }^{55}$. Several lines of investigation have indicated potential to provide a deeper understanding of ictogenesis and the pre-seizure period. Below, specific emerging areas and their implications for seizure prediction are discussed.

\section{[H2] A network theory of seizure generation}

Traditionally, seizures are thought to result from an imbalance between excitation and inhibition ${ }^{56}$ in a discrete cortical area (the seizure focus), resulting in seizure initiation, and subsequent recruitment of adjacent cortex into the escalating seizure. By contrast, the network theory proposes that even focal seizures arise from aberrant activity in a distributed network, and that a change in the configuration or in the activity of a large-scale functional network that spans lobes and hemispheres makes the brain more susceptible to seizure ${ }^{57,58}$. Many studies ${ }^{59-82}$ have indicated aberrant connectivity involving the seizure-onset zone, its surroundings and distant areas. In addition, seizure-predictive characteristics can occur in brain regions with no apparent relationship to the assumed seizure-onset zone ${ }^{83}$, thereby questioning the importance of the seizure-onset zone in the generation of a seizure. Furthermore, seizures do not occur randomly, and have been shown to have short-range ${ }^{84,85}$ and long-range temporal dependencies ${ }^{30,86}$. Development of methods to measure and track key network variables could improve seizure prediction.

Analysis techniques that enable assessment of connectivity between brain regions in a timeresolved manner on the basis of the ongoing $E E G^{83,87-90}$ in combination with the concepts of 
network theory that aim to characterize local and global properties of epileptic networks ${ }^{91-98}$ could further our understanding of how seizures emerge from an epileptic network ${ }^{99-118}$. Considering the epileptic network to be evolving rather than static could help to gain deeper insights into when and from which nodes seizures emerge ${ }^{96,99-121}$.

The challenges in the development of a network theory for seizure prediction include difficulty in sampling the evolving epileptic brain network with sufficient spatial and temporal resolution with current techniques and uncertainty about where seizures will start within the network, making it difficult to position sensors in the correct place. Advances in measurement techniques ${ }^{122}$ and conceptual advances in network theory and statistical physics will enable better definition of the epileptic network and pre-seizure changes in the network.

\section{[H2] Multi-scale electrophysiology}

Technological developments have led to use of micro-electrodes ${ }^{123,124}$ that, compared with EEG, provide new levels of temporal and spatial resolution and enable measurement of local field potentials and single neuron activity in humans during inter-ictal, pre-ictal and ictal states ${ }^{125-130}$. This technology has enabled observation of phenomena such as micro-seizures and complex interactions between neuronal groups on various spatial scales, and these observations challenge the traditional view that seizure results from a monolithic, hyper-synchronous neuronal event stemming from runaway excitation ${ }^{125-130}$.

Such high-resolution recording is an emerging area of electrophysiology that should help with interpretation of previous work conducted with macro electrophysiology. Challenges remain, such as increasing the number of neurons that can be sampled, improving spatial coverage, and clarifying the relationship between neuronal activity and EEG. Nevertheless, the processing power of wearable and implantable devices continues to accelerate, and these advances will, with time, provide the capacity for seizure prediction devices to handle the amount of data from multi-scale recordings.

\section{[H2] Multi-modal biosensing}

The use of multi-modal biosensing and emerging wearable devices is expected to improve seizure prediction (see RADAR-CNS <www.radar-cns.org>) because physiological variables can be detected through this approach that cannot be detected with traditional approaches ${ }^{4}$. Availability of a library of methods that are sensitive to different physiological variables will enable clinicians to use appropriate methods for a given individual. Several techniques and approaches, discussed below, show promise.

Neurochemistry studies in people with epilepsy and in animal models of epilepsy indicate an excess of extracellular glutamate ${ }^{131-134}$ and changes in extracellular glutamine ${ }^{135,136}$ in the seizureonset zone and zones to which the seizure spreads. Measurements in human hippocampal tissue slices have indicated an increase in glutamate in the same areas around the time of a seizure ${ }^{137}$, though whether these changes precede seizures remains to be determined ${ }^{138}$. Inhibition during the pre-ictal period might also be important, given that pre-ictal changes in $\mathrm{GABA}_{A}$ receptor-mediated chloride influx is observed in mice neurons ${ }^{139}$, and the inhibitory penumbra has a role in seizure propagation in animals and humans ${ }^{127,140}$.

Several non-neurological pre-seizure changes could also help with seizure prediction. Evidence suggests that cardiac autonomic function, cerebral haemodynamics ${ }^{141}$ (which might reflect changes in neuronal activity that are not readily detectable with EEG) and vascular coupling ${ }^{142,143}$ change in the pre-seizure period. Limited evidence also indicates pre-seizure changes in heart rate. In one small study, heart rate during the 2 minutes before onset of a focal-onset seizure was higher among people whose seizures became generalized than those whose did not ${ }^{144}$. Similarly, cardiac vagal tone, which partly controls heart rate, was higher before focal-onset seizures that became generalized than those that did not ${ }^{145}$. A meta-analysis of pre-ictal changes in heart rate suggests that such changes are observable in some, but not all, individuals, and further work is needed to determine for which patients monitoring of heart rate would be useful for seizure prediction $^{146}$. 
Several studies in childhood absence epilepsy have suggested that blood-oxygen-level-dependent activity increases several seconds before the onset of spike-wave discharges (SWDs) ${ }^{147,148}$. However, not all studies have shown this ${ }^{149}$, and whether the pre-seizure cortical phenomena are the first emergence of seizure activity or are a seizure-permissive (but otherwise normal) brain state remains unclear. Such pre-seizure activity has been observed in posterior cortical regions, especially the precuneus ${ }^{147,148,150,151}$, and in frontal cortical regions, such as the orbital and medial frontal cortex ${ }^{147,150}$. Thalamic activity was generally not seen until SWD onset, except in one study in which thalamic activity preceded SWD onset by several seconds ${ }^{152}$. In a single case report, focal-onset seizures recorded intraoperatively were preceded by a drop in oxygenated haemoglobin and an elevation in cerebral blood volume in the seizure onset region 20 seconds before electrographical changes ${ }^{153}$. In temporal lobe epilepsy, single-photon emission CT usually shows decreases in regional cerebral blood flow (rCBF) in the ictal-onset temporal lobe in the interictal state compared with that during the pre-ictal and ictal periods in the same individual and compared with that in healthy people. In individuals who, by chance, underwent single-photon emission CT 11 min and 12 min before seizure onset, rCBF was increased relative to the inter-ictal period in the same person, suggesting that rCBF increases before seizure onset ${ }^{154}$.

Studies in which transcranial magnetic stimulation has been used to assess cortical excitability ${ }^{155}$ have indicated increased excitability in people who go on to have seizures within the next 24$48 \mathrm{~h}^{156,157}$. The combination of this finding with data from computational modelling studies ${ }^{158-161}$ indicates that measurement of cortical excitability by use of a probing stimulus ${ }^{162-164}$ is an alternative to passive observation for tracking state changes in the brains of people with epilepsy.

\section{[H2] Computational modelling}

The information gathered from multi-scale and multi-modal studies of epilepsy have stimulated development of increasingly sophisticated computational modelling approaches ${ }^{165-170}$. These approaches have gained prominence over the past decade as important tools for understanding the complexity of seizures and epilepsy at various spatial and temporal scales. The spatial scales range from micro-scale modelling of single neuron behaviour to macro-scale models of brain activity, each of which can be used not only for modelling seizure-like activity and the apparently unforeseeable onset and termination of seizures, but also to gain insight into possible mechanisms of controlling seizures, such as closed-loop electrical intervention. Between these two extremes are meso-scale models, such as neural mass models ${ }^{10,171-177}$, which are intended to finely balance model simplification with biological realism to address relevant questions. In all three types of models, epilepsy is considered a dynamical brain disease ${ }^{178}$ in which the initiation of seizures can, in general, be induced by changes in network parameters or by inputs (environmental and/or endogenous) that might not always be evident to an observer ${ }^{179}$.

On the basis of key concepts from the mathematical theory of dynamical systems ${ }^{180}$, seizures are thought to be enabled by criticality - that is, the loss of balance between order and disorder in the epileptic brain ${ }^{181,182}$. In this context, a seizure represents a self-initiated and self-terminated event that emerges as a result of bistability of the brain ${ }^{161,183-185}$, a property that allows spontaneous switching from seemingly normal physiological dynamics to periods of pathological activity. Evidence indicates that such switching might not only be induced by altered properties of neurons $\underset{193}{\text { or groups of neurons, but also by changes in the gross connections of the neuronal network }}{ }^{57,186-}$

Given their increasing sophistication, computational models can help to integrate the structural, functional and dynamical properties of neural systems into a coherent view and to test in silico hypotheses concerning pre-ictal brain dynamics and their relation to endogenous and exogenous parameters that control the dynamics. Moreover, such models enable the study of aspects of the epileptic brain that cannot be explored in human studies owing to safety concerns. Such computational modelling could inform the development of methods for seizure prediction ${ }^{10}$ and of engineering techniques, such as control theory ${ }^{194}$, to determine physiological parameters that control the generation, spreading and termination of seizures over time ${ }^{174,195}$, and track brain states $^{196}$ on the basis of these parameters. The use of modelling-based approaches will allow for physiologically-informed methods of seizure prediction that offer an alternative to standard 
machine-learning techniques, which take little physiological knowledge into account and yield little insight into underlying physiology. Moreover, the combination of data and modelling will help to leverage techniques for intervention strategies and seizure control ${ }^{197,198}$.

\section{[H1] Unmet needs for clinical translation}

Collaborative efforts in the field of seizure prediction over the past three decades have resulted in a powerful international interdisciplinary effort to understand and control seizures that has led to the considerable progress discussed above. However, much remains to be completed in the coming years, and several open questions need to be answered to advance the field of seizure prediction.

\section{[H2] Understanding of seizures}

Research has demonstrated that epilepsy is a multi-scale problem ${ }^{10}$, meaning that spatially sparse recordings with few intracranial EEG electrodes are unlikely to provide a full understanding. However, whether the accurate placement of electrodes is critical for detection of seizure precursors is not known. Given the variability of seizures between people with epilepsy (and even between seizures in an individual), how to standardize electrode placement remains unclear. The minimum requirement is likely to be sampling of nodes in an individual's epileptic network that are associated with seizure precursors.

Success in seizure prediction has enormous potential to improve our understanding of seizures and epilepsy and to provide direction for research. The existence of a pre-seizure state is unproven, but is logically inferred from the predictability of seizures. What this state is and its characteristics, however, are unknown. A better understanding of the dynamic transitions into and out of seizures will contribute not only to prediction, but also to our understanding of what constitutes a seizure. Computational modeling and analysis has challenged the accepted wisdom that seizures result from out-of-control excitation and raised questions about network involvement and the role of aberrant synchronization. New computational approaches (such as those based on network theory) are also raising questions about the processes that underlie ictogenesis and epileptogenesis.

\section{[H2] Critical experiments}

With all of the aforementioned challenges in mind, critical experiments need to be performed to understand how seizures occur and how a physiological understanding can be used to predict seizures. The ideal critical experiment would be multidisciplinary, drawing on a combination of multi-scale electrophysiology and chemical physiology ${ }^{126,138,199}$, structural and functional imaging ${ }^{200}$, mathematical and computational modelling ${ }^{170}$, and potentially optogenetics ${ }^{201}$. Modelling will be important for testing hypotheses and filling in missing data when empirical methods come up short $^{10}$. These approaches should be combined to determine what seizures are and why they occur; the sequence of brain activity that leads to a seizure; whether a pro-ictal ${ }^{202}$ state of the brain makes seizures more likely or transition to seizure is deterministic (and whether this depends on the individual and the type of epilepsy); reliable and robust biomarkers of these sequences that do not result in excessive false warning time; and how these aspects are affected by infradian and multi-day cycles $^{13,15,54}$, stress and antiepileptic drugs ${ }^{164}$.

Similarly, despite good evidence that seizures are predictable, we are far from seeing a commercially-available seizure prediction device. To reach this point, crucial experimental evidence remains to be acquired. These critical studies need to incorporate the following aspects: use of continuous data rather than selected discontinuous periods; a demonstration that seizure prediction works and has benefits; the employed technology (Box 2) must be safe, reliable, stable over time, acceptable, beneficial to people with epilepsy, and applicable to and useful for a large percentage of people with epilepsy. 
Seizure prediction databases and seizure prediction contests have been valuable but suffer from limitations. Databases need to be improved to include multi-scale and multi-modal data, and monitoring should be standardized. The heterogeneity of epilepsy must also be addressed. For example, if a subset of people experience seizures that are more predictable than others, identification of these people and a better understanding of seizure generation in them could provide an invaluable foot-in-the-door for the control of seizures through seizure prediction.

With regard to seizure prediction competitions, detailed peer-reviewed accounts of the algorithms entered into the 2014 contest ${ }^{39}$ were not published, and the algorithms merely predicted whether segments of EEG recordings were from inter-ictal or pre-seizure periods rather than providing a more clinically informative evaluation of seizure prediction performance on the basis of continuous data. These contests have brought new investigators into the field and generated hypotheses about which algorithms were good predictors. Future competitions could add more value if they are based on multi-modal data and assess the computational efficiency of algorithms. Correction for multiple comparisons should be performed to account for the number of algorithms entered, and a mechanistic interpretation of the algorithm outputs should be required. An attractive possibility is the use of seizure prediction databases or competitions as objective benchmarking exercises in which algorithms are submitted to a central authority that tests them with unrevealed data. If such a process could be conducted in a manner that regulatory bodies would accept results as proof of efficacy, it would be of considerable value ${ }^{13}$.

\section{[H2] Expansion of continuous data collection}

The only system that has been used successfully for real-time, prospective seizure prediction required a brain-implantable device ${ }^{9}$, which raises ethical concerns. Non-invasive solutions, such as attachment of electrodes to the scalp, or use of a cap or headband with electrodes attached, are unlikely to be satisfactory long-term solutions because frequent maintenance would probably be required to obtain good signals, and the electrodes might be obvious and raise concerns of stigma. Semi-invasive subdermal systems might be viable alternatives, although the predictive value of data obtained in this way is unknown, and, as with intracranial electrodes, standardized placement of electrodes is not yet possible. Furthermore, the challenge of creating a system that can be used continuously for the life of an individual, including children, has not yet been tackled. If modalities other than EEG prove valuable for seizure prediction, the challenge of continous acquisition of these data must be overcome ${ }^{203-207}$.

\section{[H2] Defining outcomes relevant to patients}

People with epilepsy are vital participants in the next steps in seizure prediction, especially because the regulatory framework around such a novel approach might be uncharted. The opinions and aspirations of these individuals are essential for future planning. For example, whether a solution should be invasive or non-invasive, whether prediction needs to be $100 \%$ accurate, and whether a predictive signal alone is useful without connection to a therapy are questions best answered by people with epilepsy ${ }^{208-210}$. A short-term goal in the field might be to develop a close interaction between patient groups, researchers and industry to develop patientcentered goals.

\section{[H2] Successful trial to commercialization}

Above-chance seizure prediction based on EEG has been demonstrated in humans and animals (Box 3). Given this scientific success, an important challenge is commercialization of a seizure prediction device. The results of the clinical trial described above did not justify commercialization of the device used. The design of future trials will need to account for the lessons learned. Many studies have demonstrated that not all people with epilepsy have seizures that can be predicted, and that not all of an individual's seizures are predictable; future work will be needed to define epilepsy phenotypes or endophenotypes that are associated with predictability ${ }^{83}$. Moreover, careful work will be needed to determine several aspects, including: acceptable endpoints for regulatory 
approval, such as the predictive accuracy needed for a device to be declared effective; the goldstandard for detecting seizures, given that seizure diaries are unreliable ${ }^{9,211-213}$; whether a device that merely predicts seizures would be acceptable to regulators without being directly connected to a closed-loop delivery of treatment; and what treatment modality a device could be connected to. Currently, no attempt has been made to connect a seizure-predictive characteristic with a therapy in human trials.

\section{[H1] Guidelines revisited}

In the 2007 review of seizure prediction ${ }^{8}$, minimum requirements were proposed to ensure that published prospective and retrospective seizure prediction studies are comprehensible, comparable and assessable. These requirements stated that studies should be based on unselected continuous data, report sensitivity and specificity together with a rigorous statistical evaluation, and provide details about the studies themselves, including the use of in-sample or outof-sample testing and optimization strategies. These guidelines remain relevant, but we propose updates to complement them and account for subsequent advances in the field.

As the field moves closer to clinical trials, common standards for clinical trial reporting must be adopted. These standards include clear reporting of criteria for selection of patients and data, inclusion and exclusion criteria, documentation of the gold-standard regarding the location and types of sensors, timing and occurrence of seizures. Various measures of specificity have been published $^{8}$, and the most intuitive measure seems to be the time under false warning. Unblinded studies, especially those that are based on retrospective data, should be regarded as hypothesisgenerating only; any study that is intended to be definitive should be randomized, controlled, double-blinded and prospective, the protocol should be published, and assessment criteria for success should be clearly defined. Outcomes of these trials should be publicly available irrespective of their success to prevent unsuccessful approaches being revisited and to avoid publication bias.

For trials of wearable and implanted devices ${ }^{16,214,215}$, additional important criteria are the real-time applicability and the power-efficiency of solutions. Algorithms that need minimal computation or that can be approximated with low-power analog circuitry should be favoured. Low-complexity algorithms that perform inadequately could still provide a good benchmark for more complex algorithms. In general, algorithms that are more likely to provide a pathophysiological understanding of the disease and the ictogenic process should be favoured over others.

\section{[H1] Conclusions}

Considerable progress has been made in seizure prediction during the past three decades, especially since 2007 . Technological progress has enabled us to measure relevant signals from increasing numbers of sensors, including increasingly small sensors that enable multi-scale observation with high spatial and temporal resolution, and to collect data over longer periods of time. The progress has led to the creation of large-scale databases and seizure prediction competitions. The earlier focus on seizure prediction algorithms has continued. In addition, the practical necessities for collection, sharing and standardization of seizure prediction data are being addressed, working towards seizure prediction in wearable or implantable devices.

The formation of an international group of seizure prediction laboratories that meets regularly ${ }^{10,23,32-}$

${ }^{37}$ has led to the establishment of several international academic and industry-academic partnerships. The group has identified several of the above challenges, and articulated suggestions for addressing these challenges. We are hopeful that the remaining challenges will be solved in the near future so that seizure prediction can improve the lives of people with epilepsy.

\section{Box 1 | Defining pre-ictal biomarkers}

A pre-ictal biomarker is a predictive characteristic (or feature) derived from physiological signals (for example electroencephalography (EEG)) that becomes apparent during a defined time period 
before a seizure and does not occur at other times. Such a characteristic might or might not be visually apparent, will reflect changes in the underlying signals, and would be predictive of seizures when within a specific range of values. Characteristics are used rather than the raw signals because they simplify the essential changes in the signals. For a pre-ictal biomarker to be clinically useful in a warning system, it should become detectable early enough to minimize the time under false warning.

Characteristics that have been assessed for their predictive value, particularly those of EEG signals, range from simple to complex, and involve univariate, bivariate or multivariate linear or nonlinear analysis. The seizure prediction properties of individual characteristics can be assessed independently, but combinations of characteristics are often provided as input to pattern recognition systems, machine learning algorithms or classifiers. These classifiers enable assessment of the seizure prediction properties of characteristics in combination ${ }^{39,175,216}$.

\section{Box 2 | Future technologies, devices and industry}

One clinical trial of a prospective seizure prediction system has demonstrated that long-term intracranial recording with a brain implant is safe and feasible ${ }^{9}$. Moreover, partial success of the trial in demonstrating prospective seizure prediction in some individuals has given the field confidence to move forward, while recognizing that improvements are still needed ${ }^{13}$.

Other brain-implantable devices ${ }^{217-219}$ offer opportunities to apply and assess seizure prediction algorithms. Furthermore, minimally invasive recording techniques that position electrodes under the scalp ${ }^{220}$ are likely to open the door to more opportunities for long-term recording.

One potential application of seizure prediction is activation of seizure control ${ }^{221}$ interventions such as electrical stimulation, tissue cooling or anti-convulsant drug delivery. Two approaches to controlling seizures are possible. First, the impending seizure can be targeted, but prediction of all seizures or prevention of all seizures that are successfully predicted might not be possible.

Second, probabilistic or neuromodulatory approaches might be used to steer the brain away from a seizure-generating state and maintain the brain in a state where a seizure will not occur.

Translating a new modality from the laboratory to continuous real-world monitoring that allows individuals to go about their daily life requires a solution that is robust, long-lasting (potentially the entire life of an individual), unobtrusive, safe, efficacious and acceptable to regulatory bodies. Research and development is also required to minimize power consumption, heat generation and the form-factor, and to address device placement, retrieval and replacement. The capability to address these multiple aspects does not exist in a single institution or company, suggesting the need for collaborations to translate new insights into a successful seizure prediction device.

\section{Box 3 | Seizure prediction in animals}

Seizure prediction has been studied in many animal models of epilepsy, commonly in rats, but obtaining recordings in rats for longer than 6 months is challenging. Another challenge with animal models is translation of findings to human application. Animal models do not generalize well to humans, so predictors defined in animal models might not generalize either.

The strongest evidence that seizure prediction is possible in animals comes from long-term recordings in dogs. Studies have shown that seizure prediction performs better than chance in all dogs studied ${ }^{39,40,222}$. These results are especially important because the recordings were obtained in naturally occurring epilepsy over durations of up to 15 months, which increases confidence in the performance results achieved and that seizure prediction is possible in general.

\section{Related links}

EPILEPSIAE, www.epilepsiae.eu

IEEG.org, www.ieeg.org 
Epilepsy Ecosystem, www.epilepsyecosystem.org

American Epilepsy Society Seizure Prediction Challenge, www.kaggle.com/c/seizure-prediction

Melbourne University AES/MathWorks/NIH Seizure Prediction, https://www.kaggle.com/c/melbourne-university-seizure-prediction

RADAR-CNS https://www.radar-cns.org

\section{Key points}

- One clinical trial has shown that prospective seizure prediction in humans is possible.

- Databases of electroencepholographic data provide a standard reference for comparison of seizure prediction algorithms and for hypothesis generation.

- Competitions provide a platform for identification of the best seizure prediction algorithms.

- The network theory of epilepsy, multi-modal recording techniques, long-term monitoring, and computational modelling are providing new approaches to seizure prediction.

- The field is ready for a large-scale clinical trial of seizure prediction.

\section{Acknowledgments}

The authors acknowledge colleagues in the international seizure prediction group for valuable discussions. L.K. acknowledges funding support from the National Health and Medical Research Council (APP1130468) and the James S. McDonnell Foundation (220020419) and acknowledges the contribution of Dean R. Freestone at the University of Melbourne, Australia, to the creation of Fig. 3.

\section{Competing Interests}

The authors declare no competing interests.

\section{Author contributions}

All authors contributed equally to the conception of the Review, reviewing of the literature, writing and editing. L.K. designed the figures and tables with feedback from K.L., M.R., B.S., and H.Z.

\section{Review criteria}

We searched PubMed, Web of Science, Google Scholar, and IEEExplore with the terms "seizure prediction"', "seizure anticipation", "seizure forecasting", and "preictal"' for human and animal studies published between 1st January 2006 and 30th June 2018. We did not restrict publications by language. We also manually searched the proceedings of seizure-prediction workshops and the reference lists of papers identified and extracted relevant papers from our records.

Figure 1 | The evolution of seizure prediction. a | A timeline of the main events and findings in the field of seizure prediction. Stars indicate the times of international workshops on seizure prediction. $b \mid$ The number of papers on seizure prediction published during the past three decades (sourced via PubMed using the keywords "seizure prediction", "seizure anticipation" and "seizure forecasting").

Figure 2 | Seizure prediction systems. a | The scheme of a typical seizure prediction system. Biosignals are recorded and pre-processed. Prediction characteristics and/or pre-ictal biomarkers are then extracted from these signals. The decision system processes the temporal stream of prediction characteristic values and detects changes that indicate an impending seizure. To reach a decision, thresholds can be set for characteristics, or classifiers can be used to make decisions 
on the basis of multiple characteristics. The decision system then engages the advisory system, which warns the patient if a seizure is likely to occur in the near future. Dashed lines indicate the possibility of closed-loop seizure control. b | An ambulatory seizure warning system that implements the open-loop seizure prediction approach in part a. Electrodes are implanted on the surface of the cerebral cortex for intracranial electroencephalography (EEG). Recordings are transmitted to an external advisory device via an implanted telemetry unit. c | Seizure prediction in practice. Continuous intracranial EEG records brain activity (black solid lines). Time series of predictive characteristics (green line) can be derived from the intracranial EEG recording and a threshold set (black dashed line) to predict (red rectangles) whether a seizure is likely to occur.

Figure 3 | Evaluation of seizure prediction algorithms. Prediction performance is evaluated on the basis of receiver operating characteristic (ROC) curves that relate true positive rates to false positive rates. Area under the curve (AUC) can be used to quantify algorithm performance (a perfect predictor has an AUC of 1). Coloured lines indicate example performance levels of algorithms.

\section{References}

1 Banerjee, P. N., Filippi, D. \& Allen Hauser, W. The descriptive epidemiology of epilepsy-a review. Epilepsy Res. 85, 31-45, (2009).

2 Kwan, P., Schachter, S. C. \& Brodie, M. J. Drug-resistant epilepsy. N. Engl. J. Med. 365, 919-926, (2011).

3 Ridsdale, L., Charlton, J., Ashworth, M., Richardson, M. P. \& Gulliford, M. C. Epilepsy mortality and risk factors for death in epilepsy: a population-based study. Br. J. Gen. Pract. 61, e271-278, (2011).

4 Dumanis, S. B., French, J. A., Bernard, C., Worrell, G. A. \& Fureman, B. E. Seizure Forecasting from Idea to Reality. Outcomes of the My Seizure Gauge Epilepsy Innovation Institute Workshop. eNeuro 4, ENEURO. 0349-0317.2017, (2017).

5 Epilepsy-Foundation. Ei2 community survey. https://www.epilepsy.com/makedifference/research-and-new-therapies/innovation/epilepsy-innovation-institute/seizuregauge. (2016).

6 Nickel, R. et al. Quality of life issues and occupational performance of persons with epilepsy. Arq. Neuropsiquiatr. 70, 140-144, (2012).

7 Fisher, R. S. et al. The impact of epilepsy from the patient's perspective I. Descriptions and subjective perceptions. Epilepsy Res. 41, 39-51, (2000).

8 Mormann, F., Andrzejak, R. G., Elger, C. E. \& Lehnertz, K. Seizure prediction: the long and winding road. Brain 130, 314-333, (2007).

9 Cook, M. J. et al. Prediction of seizure likelihood with a long-term, implanted seizure advisory system in patients with drug-resistant epilepsy: a first-in-man study. Lancet Neurol. 12, 563-571, (2013).

10 Kuhlmann, L., Grayden, D. B., Wendling, F. \& Schiff, S. J. Role of multiple-scale modeling of epilepsy in seizure forecasting. J. Clin. Neurophysiol. 32, 220-226, (2015).

11 Snyder, D. E., Echauz, J., Grimes, D. B. \& Litt, B. The statistics of a practical seizure warning system. J Neural Eng 5, 392-401, (2008).

12 Winterhalder, M. et al. The seizure prediction characteristic: a general framework to assess and compare seizure prediction methods. Epilepsy Behav. 4, 318-325, (2003).

13 Kuhlmann, L. et al. Epilepsyecosystem.org: Crowd-Sourcing Reproducible Seizure Prediction with Long-Term Human Intracranial EEG. Brain, In Press, (2018).

14 Gadhoumi, K., Gotman, J. \& Lina, J. M. Scale invariance properties of intracerebral EEG improve seizure prediction in mesial temporal lobe epilepsy. PLoS One 10, e0121182, (2015).

15 Karoly, P. J. et al. The circadian profile of epilepsy improves seizure forecasting. Brain 140, 2169-2182, (2017).

16 Kiral-Kornek, I. et al. Epileptic Seizure Prediction Using Big Data and Deep Learning: Toward a Mobile System. Ebiomedicine 27, 103-111, (2018). 
Truong, N. D. et al. Convolutional Neural Network for Seizure Prediction using Intracranial and Scalp Electroencephalogram. Neural Netw., In Press, (2018).

18 Kuhlmann, L. et al. Patient-specific bivariate-synchrony-based seizure prediction for short prediction horizons. Epi. Res. 91, 214-231, (2010).

19 Schelter, B. et al. Testing statistical significance of multivariate time series analysis techniques for epileptic seizure prediction. Chaos 16, 013108, (2006).

20 Andrzejak, R. G. et al. Testing the null hypothesis of the nonexistence of a preseizure state. Phys. Rev. E Stat. Nonlin. Soft Matter Phys. 67, 010901, (2003).

21 Andrzejak, R. G., Chicharro, D., Elger, C. E. \& Mormann, F. Seizure prediction: any better than chance? Clin. Neurophysiol. 120, 1465-1478, (2009).

22 Kreuz, T. et al. Measure profile surrogates: a method to validate the performance of epileptic seizure prediction algorithms. Phys. Rev. E Stat. Nonlin. Soft Matter Phys. 69, 061915, (2004).

23 Lehnertz, K. \& Litt, B. The First International Collaborative Workshop on Seizure Prediction: summary and data description. Clin. Neurophysiol. 116, 493-505, (2005).

24 Ihle, M. et al. EPILEPSIAE-A European epilepsy database. Comput. Methods Programs Biomed. 106, 127-138, (2012).

25 Klatt, J. et al. The EPILEPSIAE database: an extensive electroencephalography database of epilepsy patients. Epilepsia 53, 1669-1676, (2012).

26 Wagenaar, J. B. et al. Collaborating and sharing data in epilepsy research. J. Clin. Neurophysiol. 32, 235-239, (2015).

27 Kini, L. G., Davis, K. A. \& Wagenaar, J. B. Data integration: Combined imaging and electrophysiology data in the cloud. Neuroimage 124, 1175-1181, (2016).

28 Schelter, B. et al. Do False Predictions of Seizures Depend on the State of Vigilance? A Report from Two Seizure-Prediction Methods and Proposed Remedies. Epilepsia 47, 20582070, (2006).

29 Freestone, D. R., Karoly, P. J. \& Cook, M. J. A forward-looking review of seizure prediction. Curr. Opin. Neurol. 30, 167-173, (2017).

30 Cook, M. J. et al. The dynamics of the epileptic brain reveal long-memory processes. Front. Neurol. 5, 217, (2014).

31 Cook, M. J. et al. Human focal seizures are characterized by populations of fixed duration and interval. Epilepsia 57, 359-368, (2016).

32 Gluckman, B. J. \& Schevon, C. A. Seizure Prediction 6: From Mechanisms to Engineered Interventions for Epilepsy. J. Clin. Neurophysiol. 32, 181-187, (2015).

33 Kuhlmann, L., Grayden, D. B. \& Cook, M. J. Special Issue on Epilepsy Mechanisms, Models, Prediction and Control. Int. J. Neural Syst. 27, 1702001, (2017).

34 Osorio, I., Zaveri, H. P., Frei, M. G. \& Arthurs, S. in Epilepsy: The Intersection of Neurosciences, Biology, Mathematics, Engineering, and Physics (CRC Press, 2011).

35 Richardson, M. P. \& Jefferys, J. G. Introduction-Epilepsy Research UK Workshop 2010 on "Preictal Phenomena". Epilepsy Res. 97, 229-230, (2011).

36 Schelter, B., Timmer, J. \& Schulze-Bonhage, A. Seizure prediction in epilepsy: from basic mechanisms to clinical applications. (John Wiley \& Sons, 2008).

37 Tetzlaff, R., Elger, C. E. \& Lehnertz, K. in Recent Advances in Predicting and Preventing Epileptic Seizures (World Scientific, 2013).

38 Zaveri, H. P., Frei, M. G., Arthurs, S. \& Osorio, I. Seizure prediction: the Fourth International Workshop. Epilepsy Behav. 19, 1-3, (2010).

39 Brinkmann, B. H. et al. Crowdsourcing reproducible seizure forecasting in human and canine epilepsy. Brain 139, 1713-1722, (2016).

40 Howbert, J. J. et al. Forecasting seizures in dogs with naturally occurring epilepsy. PLoS One 9, e81920, (2014).

41 Karoly, P. J. et al. Interictal spikes and epileptic seizures: their relationship and underlying rhythmicity. Brain 139, 1066-1078, (2016).

42 Payne, D. E. et al. Postictal suppression and seizure durations: A patient-specific, longterm iEEG analysis. Epilepsia 59, 1027-1036, (2018).

43 Lange, H. H., Lieb, J. P., Engel, J., Jr. \& Crandall, P. H. Temporo-spatial patterns of preictal spike activity in human temporal lobe epilepsy. Electroencephalogr. Clin. Neurophysiol. 56, 543-555, (1983). 
Katz, A., Marks, D. A., McCarthy, G. \& Spencer, S. S. Does interictal spiking change prior to seizures? Electroencephalogr. Clin. Neurophysiol. 79, 153-156, (1991).

45 Gotman, J. Relationships between Interictal Spiking and Seizures - Human and Experimental-Evidence. Can. J. Neurol. Sci. 18, 573-576, (1991).

46 Malow, B. A., Lin, X., Kushwaha, R. \& Aldrich, M. S. Interictal spiking increases with sleep depth in temporal lobe epilepsy. Epilepsia 39, 1309-1316, (1998).

47 Li, S. F., Zhou, W. D., Yuan, Q. \& Liu, Y. X. Seizure Prediction Using Spike Rate of Intracranial EEG. IEEE Trans. Neural Syst. Rehabil. Eng. 21, 880-886, (2013).

48 Wasade, V. S. et al. Intracranial electrographic analysis of preictal spiking and ictal onset in uni- and bitemporal epilepsy. Epileptic Disord. 17, 156-164, (2015).

49 Goncharova, Il et al. The relationship between seizures, interictal spikes and antiepileptic drugs. Clin. Neurophysiol. 127, 3180-3186, (2016).

50 Goncharova, II, Zaveri, H. P., Duckrow, R. B., Novotny, E. J. \& Spencer, S. S. Spatial distribution of intracranially recorded spikes in medial and lateral temporal epilepsies. Epilepsia 50, 2575-2585, (2009).

51 Goncharova, II et al. Intracranially recorded interictal spikes: relation to seizure onset area and effect of medication and time of day. Clin. Neurophysiol. 124, 2119-2128, (2013).

52 Spencer, S. S., Goncharova, II, Duckrow, R. B., Novotny, E. J. \& Zaveri, H. P. Interictal spikes on intracranial recording: behavior, physiology, and implications. Epilepsia 49, 18811892, (2008).

53 Abou-Khalil, B. The ambiguous relationship between spikes and seizures. Clin. Neurophysiol. 127, 3176-3177, (2016).

54 Baud, M. O. et al. Multi-day rhythms modulate seizure risk in epilepsy. Nature communications 9, 88, (2018).

55 Gotman, J. A few thoughts on "What is a seizure?". Epilepsy Behav. 22, S2-S3, (2011).

56 Staley, K. Molecular mechanisms of epilepsy. Nat. Neurosci. 18, 367-372, (2015).

57 Terry, J. R., Benjamin, O. \& Richardson, M. P. Seizure generation: the role of nodes and networks. Epilepsia 53, e166-169, (2012).

58 Blumenfeld, H. Cellular and network mechanisms of spike-wave seizures. Epilepsia 46 Suppl 9, 21-33, (2005).

59 Schevon, C. A. et al. Cortical abnormalities in epilepsy revealed by local EEG synchrony. Neuroimage 35, 140-148, (2007).

60 Ortega, G. J., Menendez de la Prida, L., Sola, R. G. \& Pastor, J. Synchronization clusters of interictal activity in the lateral temporal cortex of epileptic patients: intraoperative electrocorticographic analysis. Epilepsia 49, 269-280, (2008).

61 Gazit, T. et al. Time-frequency characterization of electrocorticographic recordings of epileptic patients using frequency-entropy similarity: a comparison to other bi-variate measures. J. Neurosci. Methods 194, 358-373, (2011).

62 Palmigiano, A., Pastor, J., Garcia de Sola, R. \& Ortega, G. J. Stability of synchronization clusters and seizurability in temporal lobe epilepsy. PLoS ONE [Electronic Resource] 7, e41799, (2012).

63 Towle, V. L., Carder, R. K., Khorasani, L. \& Lindberg, D. Electrocorticographic coherence patterns. J. Clin. Neurophysiol. 16, 528-547, (1999).

64 Towle, V. L. et al. Identification of the sensory/motor area and pathologic regions using ECoG coherence. Electroencephalogr. Clin. Neurophysiol. 106, 30-39, (1998).

65 Zaveri, H. P. et al. Localization-related epilepsy exhibits significant connectivity away from the seizure-onset area. Neuroreport 20, 891-895, (2009).

66 Zaveri, H. P., Pincus, S. M., Goncharova, I. I., Duckrow, R. B. \& Spencer, S. S. in Proc. of SPIE. 70740T-70741.

67 Frei, M. G. et al. Controversies in epilepsy: debates held during the Fourth International Workshop on Seizure Prediction. Epilepsy Behav. 19, 4-16, (2010).

68 Warren, C. P. et al. Synchrony in normal and focal epileptic brain: the seizure onset zone is functionally disconnected. J. Neurophysiol. 104, 3530-3539, (2010).

69 Varotto, G., Tassi, L., Franceschetti, S., Spreafico, R. \& Panzica, F. Epileptogenic networks of type II focal cortical dysplasia: a stereo-EEG study. Neuroimage 61, 591-598, (2012). 
Tomlinson, S. B., Porter, B. E. \& Marsh, E. D. Interictal network synchrony and local heterogeneity predict epilepsy surgery outcome among pediatric patients. Epilepsia 58, 402-411, (2017).

71 Sinha, N. et al. Predicting neurosurgical outcomes in focal epilepsy patients using computational modelling. Brain 140, 319-332, (2017).

72 Eissa, T. L. \& Schevon, C. A. The role of computational modelling in seizure localization. Brain 140, 254-256, (2017).

73 Lee, H. W. et al. Altered functional connectivity in seizure onset zones revealed by fMRI intrinsic connectivity. Neurology 83, 2269-2277, (2014).

74 Constable, R. T. et al. Potential use and challenges of functional connectivity mapping in intractable epilepsy. Front. Neurol. 4, 39, (2013).

75 Zhang, X. et al. Social network theory applied to resting-state fMRI connectivity data in the identification of epilepsy networks with iterative feature selection. J. Neurosci. Methods 199, 129-139, (2011).

76 Negishi, M., Martuzzi, R., Novotny, E. J., Spencer, D. D. \& Constable, R. T. Functional MRI connectivity as a predictor of the surgical outcome of epilepsy. Epilepsia 52, 1733-1740, (2011).

77 Elisevich, K. et al. An assessment of MEG coherence imaging in the study of temporal lobe epilepsy. Epilepsia 52, 1110-1119, (2011).

78 Nissen, I. A. et al. Identifying the epileptogenic zone in interictal resting-state MEG sourcespace networks. Epilepsia 58, 137-148, (2017).

79 Englot, D. J. et al. Epileptogenic zone localization using magnetoencephalography predicts seizure freedom in epilepsy surgery. Epilepsia 56, 949-958, (2015).

80 Englot, D. J. et al. Global and regional functional connectivity maps of neural oscillations in focal epilepsy. Brain 138, 2249-2262, (2015).

81 Englot, D. J., Konrad, P. E. \& Morgan, V. L. Regional and global connectivity disturbances in focal epilepsy, related neurocognitive sequelae, and potential mechanistic underpinnings. Epilepsia 57, 1546-1557, (2016).

82 Dickten, H., Porz, S., Elger, C. E. \& Lehnertz, K. Weighted and directed interactions in evolving large-scale epileptic brain networks. Sci. Rep. 6, 34824, (2016).

83 Lehnertz, K., Dickten, H., Porz, S., Helmstaedter, C. \& Elger, C. E. Predictability of uncontrollable multifocal seizures - towards new treatment options. Sci. Rep. 6, 24584, (2016).

84 Sunderam, S., Osorio, I. \& Frei, M. G. Epileptic seizures are temporally interdependent under certain conditions. Epilepsy Res. 76, 77-84, (2007).

85 Ouyang, G., Li, X., Dang, C. \& Richards, D. A. Using recurrence plot for determinism analysis of EEG recordings in genetic absence epilepsy rats. Clin. Neurophysiol. 119, 1747-1755, (2008).

86 Ngamga, E. J. et al. Evaluation of selected recurrence measures in discriminating pre-ictal and inter-ictal periods from epileptic EEG data. Phys Lett $A$ 380, 1419-1425, (2016).

87 Staniek, M. \& Lehnertz, K. Symbolic transfer entropy: inferring directionality in biosignals. Biomed. Tech. (Berl.) 54, 323-328, (2009).

88 Stamoulis, C., Gruber, L. J., Schomer, D. L. \& Chang, B. S. High-frequency neuronal network modulations encoded in scalp EEG precede the onset of focal seizures. Epilepsy Behav. 23, 471-480, (2012).

89 Dickten, H. \& Lehnertz, K. Identifying delayed directional couplings with symbolic transfer entropy. Phys. Rev. E Stat. Nonlin. Soft Matter Phys. 90, 062706, (2014).

90 Lehnertz, K. \& Dickten, H. Assessing directionality and strength of coupling through symbolic analysis: an application to epilepsy patients. Philos TR Soc A 373, 20140094, (2015).

91 Reijneveld, J. C., Ponten, S. C., Berendse, H. W. \& Stam, C. J. The application of graph theoretical analysis to complex networks in the brain. Clin. Neurophysiol. 118, 2317-2331, (2007).

92 Bullmore, E. \& Sporns, O. Complex brain networks: graph theoretical analysis of structural and functional systems. Nat. Rev. Neurosci. 10, 186-198, (2009).

93 Richardson, M. Current themes in neuroimaging of epilepsy: brain networks, dynamic phenomena, and clinical relevance. Clin. Neurophysiol. 121, 1153-1175, (2010). 
94 Kramer, M. A. \& Cash, S. S. Epilepsy as a Disorder of Cortical Network Organization. Neuroscientist 18, 360-372, (2012).

95 van Diessen, E., Diederen, S. J. H., Braun, K. P. J., Jansen, F. E. \& Stam, C. J. Functional and structural brain networks in epilepsy: What have we learned? Epilepsia 54, 1855-1865, (2013).

96 Lehnertz, K. et al. Evolving networks in the human epileptic brain. Physica D-Nonlinear Phenomena 267, 7-15, (2014).

97 Stam, C. J. Modern network science of neurological disorders. Nat. Rev. Neurosci. 15, 683695, (2014).

98 Yaffe, R. B. et al. Physiology of functional and effective networks in epilepsy. Clin. Neurophysiol. 126, 227-236, (2015).

99 Bertram, E. H., Zhang, D. X., Mangan, P., Fountain, N. \& Rempe, D. Functional anatomy of limbic epilepsy: a proposal for central synchronization of a diffusely hyperexcitable network. Epilepsy Res. 32, 194-205, (1998).

100 Bragin, A., Wilson, C. L. \& Engel, J., Jr. Chronic epileptogenesis requires development of a network of pathologically interconnected neuron clusters: a hypothesis. Epilepsia $\mathbf{4 1}$ Suppl 6, S144-152, (2000).

101 Spencer, S. S. Neural networks in human epilepsy: evidence of and implications for treatment. Epilepsia 43, 219-227, (2002).

102 Schindler, K., Leung, H., Elger, C. E. \& Lehnertz, K. Assessing seizure dynamics by analysing the correlation structure of multichannel intracranial EEG. Brain 130, 65-77, (2007).

103 Schindler, K., Elger, C. E. \& LehnertZ, K. Increasing synchronization may promote seizure termination: Evidence from status epilepticus. Clin. Neurophysiol. 118, 1955-1968, (2007).

104 Kramer, M. A., Kolaczyk, E. D. \& Kirsch, H. E. Emergent network topology at seizure onset in humans. Epilepsy Res. 79, 173-186, (2008).

105 Schindler, K. A., Bialonski, S., Horstmann, M. T., Elger, C. E. \& Lehnertz, K. Evolving functional network properties and synchronizability during human epileptic seizures. Chaos 18, 033119, (2008).

106 Valton, L. et al. Functional interactions in brain networks underlying epileptic seizures in bilateral diffuse periventricular heterotopia. Clin. Neurophysiol. 119, 212-223, (2008).

107 Kramer, M. A. et al. Coalescence and fragmentation of cortical networks during focal seizures. J. Neurosci. 30, 10076-10085, (2010).

108 Bialonski, S., Wendler, M. \& Lehnertz, K. Unraveling spurious properties of interaction networks with tailored random networks. PLoS One 6, e22826, (2011).

109 Kramer, M. A. et al. Human seizures self-terminate across spatial scales via a critical transition. Proc. Natl. Acad. Sci. U. S. A. 109, 21116-21121, (2012).

110 Stamoulis, C., Schomer, D. L. \& Chang, B. S. Information theoretic measures of network coordination in high-frequency scalp EEG reveal dynamic patterns associated with seizure termination. Epilepsy Res. 105, 299-315, (2013).

111 Liao, W. et al. Dynamical intrinsic functional architecture of the brain during absence seizures. Brain Struct Funct 219, 2001-2015, (2014).

112 Afra, P., Jouny, C. C. \& Bergey, G. K. Termination patterns of complex partial seizures: An intracranial EEG study. Seizure 32, 9-15, (2015).

113 Geier, C., Bialonski, S., Elger, C. E. \& Lehnertz, K. How important is the seizure onset zone for seizure dynamics? Seizure 25, 160-166, (2015).

114 Steimer, A., Zubler, F. \& Schindler, K. Chow-Liu trees are sufficient predictive models for reproducing key features of functional networks of periictal EEG time-series. Neuroimage 118, 520-537, (2015).

115 Gupta, D., Ossenblok, P. \& van Luijtelaar, G. Space-time network connectivity and cortical activations preceding spike wave discharges in human absence epilepsy: a MEG study. Med. Biol. Eng. Comput. 49, 555-565, (2011).

116 Takahashi, H., Takahashi, S., Kanzaki, R. \& Kawai, K. State-dependent precursors of seizures in correlation-based functional networks of electrocorticograms of patients with temporal lobe epilepsy. Neurol. Sci. 33, 1355-1364, (2012). 
117 Clemens, B. et al. Neurophysiology of juvenile myoclonic epilepsy: EEG-based network and graph analysis of the interictal and immediate preictal states. Epilepsy Res. 106, 357-369, (2013).

118 Geier, C. \& Lehnertz, K. Long-term variability of importance of brain regions in evolving epileptic brain networks. Chaos 27, 043112, (2017).

119 Burns, S. P. et al. Network dynamics of the brain and influence of the epileptic seizure onset zone. Proc. Natl. Acad. Sci. U. S. A. 111, E5321-5330, (2014).

120 Kuhnert, M. T., Elger, C. E. \& Lehnertz, K. Long-term variability of global statistical properties of epileptic brain networks. Chaos 20, 043126, (2010).

121 Geier, C., Lehnertz, K. \& Bialonski, S. Time-dependent degree-degree correlations in epileptic brain networks: from assortative to dissortative mixing. Front. Hum. Neurosci. 9 , 462, (2015).

122 Spencer, D. D., Gerrard, J. L. \& Zaveri, H. P. The roles of surgery and technology in understanding focal epilepsy and its comorbidities. Lancet Neurol. 17, 373-382, (2018).

123 Deisseroth, K. \& Schnitzer, M. J. Engineering approaches to illuminating brain structure and dynamics. Neuron 80, 568-577, (2013).

124 Patil, A. C. \& Thakor, N. V. Implantable neurotechnologies: a review of micro- and nanoelectrodes for neural recording. Med. Biol. Eng. Comput. 54, 23-44, (2016).

125 Stead, M. et al. Microseizures and the spatiotemporal scales of human partial epilepsy. Brain 133, 2789-2797, (2010).

126 Truccolo, W. et al. Single-neuron dynamics in human focal epilepsy. Nat. Neurosci. 14, 635-641, (2011).

127 Schevon, C. A. et al. Evidence of an inhibitory restraint of seizure activity in humans. Nature communications 3, 1060, (2012).

$128 \mathrm{Hu}, \mathrm{S}$. Q. et al. Increase trend of correlation and phase synchrony of microwire iEEG before macroseizure onset. Cogn. Neurodyn. 8, 111-126, (2014).

129 Gast, H. et al. Burst firing of single neurons in the human medial temporal lobe changes before epileptic seizures. Clin. Neurophysiol. 127, 3329-3334, (2016).

130 Smith, E. H. et al. The ictal wavefront is the spatiotemporal source of discharges during spontaneous human seizures. Nature communications 7, 11098, (2016).

131 Petroff, O. A. et al. Glutamate-glutamine cycling in the epileptic human hippocampus. Epilepsia 43, 703-710, (2002).

132 Cavus, I. et al. Extracellular metabolites in the cortex and hippocampus of epileptic patients. Ann. Neurol. 57, 226-235, (2005).

133 DiNuzzo, M., Mangia, S., Maraviglia, B. \& Giove, F. Physiological bases of the K+ and the glutamate/GABA hypotheses of epilepsy. Epilepsy Res. 108, 995-1012, (2014).

134 Stephens, M. L. et al. Tonic glutamate in CA1 of aging rats correlates with phasic glutamate dysregulation during seizure. Epilepsia 55, 1817-1825, (2014).

135 Kanamori, K. \& Ross, B. D. Chronic electrographic seizure reduces glutamine and elevates glutamate in the extracellular fluid of rat brain. Brain Res. 1371, 180-191, (2011).

136 Kanamori, K. \& Ross, B. D. Electrographic seizures are significantly reduced by in vivo inhibition of neuronal uptake of extracellular glutamine in rat hippocampus. Epilepsy Res. 107, 20-36, (2013).

137 During, M. J. \& Spencer, D. D. Extracellular hippocampal glutamate and spontaneous seizure in the conscious human brain. Lancet 341, 1607-1610, (1993).

138 Huberfeld, G. et al. Glutamatergic pre-ictal discharges emerge at the transition to seizure in human epilepsy. Nat. Neurosci. 14, 627-U121, (2011).

139 Lillis, K. P., Kramer, M. A., Mertz, J., Staley, K. J. \& White, J. A. Pyramidal cells accumulate chloride at seizure onset. Neurobiol. Dis. 47, 358-366, (2012).

140 Smith, E. H. et al. The ictal wavefront is the spatiotemporal source of discharges during spontaneous human seizures. Nature communications 7, 11098, (2016).

141 Tewolde, S., Oommen, K., Lie, D. Y., Zhang, Y. \& Chyu, M. C. Epileptic Seizure Detection and Prediction Based on Continuous Cerebral Blood Flow Monitoring--a Review. J Healthc Eng 6, 159-178, (2015).

142 Schwartz, T. H., Hong, S. B., Bagshaw, A. P., Chauvel, P. \& Benar, C. G. Preictal changes in cerebral haemodynamics: review of findings and insights from intracerebral EEG.

Epilepsy Res. 97, 252-266, (2011). 
143 Patel, K. S., Zhao, M., Ma, H. \& Schwartz, T. H. Imaging preictal hemodynamic changes in neocortical epilepsy. Neurosurg. Focus 34, E10, (2013).

144 Nilsen, K. B., Haram, M., Tangedal, S., Sand, T. \& Brodtkorb, E. Is elevated pre-ictal heart rate associated with secondary generalization in partial epilepsy? Seizure 19, 291-295, (2010).

145 Delamont, R. S., Julu, P. O. O. \& Jamal, G. A. Changes in a measure of cardiac vagal activity before and after epileptic seizures. Epilepsy Res. 35, 87-94, (1999).

146 Bruno, E., Biondi, A., Richardson, M. P. \& RADAR-CNS-Consortium. Pre-ictal heart rate changes: A systematic review and meta-analysis. Seizure 55, 48-56, (2018).

147 Benuzzi, F. et al. Increased cortical BOLD signal anticipates generalized spike and wave discharges in adolescents and adults with idiopathic generalized epilepsies. Epilepsia 53, 622-630, (2012).

148 Masterton, R. A., Carney, P. W., Abbott, D. F. \& Jackson, G. D. Absence epilepsy subnetworks revealed by event-related independent components analysis of functional magnetic resonance imaging. Epilepsia 54, 801-808, (2013).

149 Moeller, F. et al. Simultaneous EEG-fMRI in drug-naive children with newly diagnosed absence epilepsy. Epilepsia 49, 1510-1519, (2008).

150 Bai, X. et al. Dynamic time course of typical childhood absence seizures: EEG, behavior, and functional magnetic resonance imaging. J. Neurosci. 30, 5884-5893, (2010).

151 Carney, P. W. et al. The core network in absence epilepsy. Differences in cortical and thalamic BOLD response. Neurology 75, 904-911, (2010).

152 Moeller, F. et al. Changes in activity of striato-thalamo-cortical network precede generalized spike wave discharges. Neuroimage 39, 1839-1849, (2008).

153 Zhao, M. et al. Focal increases in perfusion and decreases in hemoglobin oxygenation precede seizure onset in spontaneous human epilepsy. Epilepsia 48, 2059-2067, (2007).

154 Baumgartner, C. et al. Preictal SPECT in temporal lobe epilepsy: Regional cerebral blood flow is increased prior to electroencephalography-seizure onset. J. Nucl. Med. 39, 978-982, (1998).

155 Bauer, P. R., Kalitzin, S., Zijlmans, M., Sander, J. W. \& Visser, G. H. Cortical Excitability as a Potential Clinical Marker of Epilepsy: A Review of the Clinical Application of Transcranial Magnetic Stimulation. Int. J. Neural Syst. 24, 1430001, (2014).

156 Wright, M. A., Orth, M., Patsalos, P. N., Smith, S. J. \& Richardson, M. P. Cortical excitability predicts seizures in acutely drug-reduced temporal lobe epilepsy patients. Neurology 67, 1646-1651, (2006).

157 Badawy, R., Macdonell, R., Jackson, G. \& Berkovic, S. The peri-ictal state: cortical excitability changes within $24 \mathrm{~h}$ of a seizure. Brain 132, 1013-1021, (2009).

158 Suffczynski, P. et al. Active paradigms of seizure anticipation: computer model evidence for necessity of stimulation. Phys. Rev. E Stat. Nonlin. Soft Matter Phys. 78, 051917, (2008).

159 O'Sullivan-Greene, E., Mareels, I., Freestone, D., Kulhmann, L. \& Burkitt, A. in Annual International Conference of the IEEE Engineering in Medicine and Biology Society. (IEEE. p. 6428-6431).

160 Kalitzin, S. N., Velis, D. N. \& da Silva, F. H. Stimulation-based anticipation and control of state transitions in the epileptic brain. Epilepsy Behav. 17, 310-323, (2010).

161 Kalitzin, S., Koppert, M., Petkov, G., Velis, D. \& da Silva, F. L. Computational model prospective on the observation of proictal states in epileptic neuronal systems. Epilepsy Behav. 22 Suppl 1, S102-109, (2011).

162 Bruzzo, A. A., Gesierich, B., Rubboli, G. \& Vimal, R. L. Predicting epileptic seizures with a mental simulation task: a prospective study. Epilepsy Behav. 13, 256-259, (2008).

163 Freestone, D. R. et al. Electrical probing of cortical excitability in patients with epilepsy. Epilepsy Behav. 22 Suppl 1, S110-118, (2011).

164 Meisel, C. et al. Intrinsic excitability measures track antiepileptic drug action and uncover increasing/decreasing excitability over the wake/sleep cycle. Proc. Natl. Acad. Sci. U. S. A. 112, 14694-14699, (2015).

165 Lytton, W. W. Computer modelling of epilepsy. Nat. Rev. Neurosci. 9, 626-637, (2008).

166 Soltesz, I. \& Staley, K. Computational neuroscience in epilepsy. Vol. 6 (Academic Press, 2008). 
167 Stefanescu, R. A., Shivakeshavan, R. G. \& Talathi, S. S. Computational models of epilepsy. Seizure 21, 748-759, (2012).

168 Volman, V., Bazhenov, M. \& Sejnowski, T. J. Computational models of neuron-astrocyte interaction in epilepsy. Front. Comput. Neurosci. 6, 58, (2012).

169 Holt, A. B. \& Netoff, T. I. Computational modeling of epilepsy for an experimental neurologist. Exp. Neurol. 244, 75-86, (2013).

170 Wendling, F., Benquet, P., Bartolomei, F. \& Jirsa, V. Computational models of epileptiform activity. J. Neurosci. Methods 260, 233-251, (2016).

171 Chakravarthy, N., Sabesan, S., Tsakalis, K. \& lasemidis, L. Controlling epileptic seizures in a neural mass model. Journal of Combinatorial Optimization 17, 98-116, (2009).

172 Shayegh, F., Fattahi, R. A., Sadri, S. \& Ansari-Asl, K. A Brief Survey of Computational Models of Normal and Epileptic EEG Signals: A Guideline to Model-based Seizure Prediction. J Med Signals Sens 1, 62-72, (2011).

173 Shayegh, F., Sadri, S., Amirfattahi, R. \& Ansari-Asl, K. Proposing a two-level stochastic model for epileptic seizure genesis. J. Comput. Neurosci. 36, 39-53, (2014).

174 Freestone, D. et al. Patient-specific neural mass modelling: stochastic and deterministic methods. Recent Advances in Predicting and Preventing Epileptic Seizures, 63-82, (2013).

175 Freestone, D. R. et al. Seizure Prediction: Science Fiction or Soon to Become Reality? Curr. Neurol. Neurosci. Rep. 15, 73, (2015).

176 Aram, P., Freestone, D. R., Cook, M. J., Kadirkamanathan, V. \& Grayden, D. B. Modelbased estimation of intra-cortical connectivity using electrophysiological data. Neuroimage 118, 563-575, (2015).

177 Watson, P. D., Horecka, K. M., Cohen, N. J. \& Ratnam, R. A Phase-Locked Loop Epilepsy Network Emulator. Neurocomputing 173, 1245-1249, (2016).

178 Milton, J. G. Epilepsy as a dynamic disease: A tutorial of the past with an eye to the future. Epilepsy Behav. 18, 33-44, (2010).

179 Lopes da Silva, F., Blanes, W., Parra, S. N. K. J., Suffczynski, P. \& Velis, D. N. Epilepsies as dynamical diseases of brain systems: basic models of the transition between normal and epileptic activity. Epilepsia 44 (Suppl. 12), 72-83, (2003).

180 Rabinovich, M. I., Varona, P., Selverston, A. I. \& Abarbanel, H. D. I. Dynamical principles in neuroscience. Rev Mod Phys 78, 1213-1265, (2006).

181 Meisel, C., Storch, A., Hallmeyer-Elgner, S., Bullmore, E. \& Gross, T. Failure of adaptive self-organized criticality during epileptic seizure attacks. PLoS Comput. Biol. 8, e1002312, (2012).

182 Milton, J. G. Neuronal avalanches, epileptic quakes and other transient forms of neurodynamics. Eur. J. Neurosci. 36, 2156-2163, (2012).

183 Suffczynski, P., Kalitzin, S. \& Lopes Da Silva, F. H. Dynamics of non-convulsive epileptic phenomena modeled by a bistable neuronal network. Neuroscience 126, 467-484, (2004).

184 Takeshita, D., Sato, Y. D. \& Bahar, S. Transitions between multistable states as a model of epileptic seizure dynamics. Phys. Rev. E Stat. Nonlin. Soft Matter Phys. 75, 051925, (2007).

185 Jirsa, V. K., Stacey, W. C., Quilichini, P. P., Ivanov, A. I. \& Bernard, C. On the nature of seizure dynamics. Brain 137, 2210-2230, (2014).

186 Feldt, S., Osterhage, H., Mormann, F., Lehnertz, K. \& Zochowski, M. Internetwork and intranetwork communications during bursting dynamics: Applications to seizure prediction. Phys. Rev. E Stat. Nonlin. Soft Matter Phys. 76, 021920, (2007).

187 Rothkegel, A. \& Lehnertz, K. Multistability, local pattern formation, and global collective firing in a small-world network of non-leaky integrate-and-fire neurons. Chaos 19, 015109 , (2009).

188 Rothkegel, A. \& Lehnertz, K. Recurrent events of synchrony in complex networks of pulsecoupled oscillators. Epl-Europhys Lett 95, 38001, (2011).

189 Anderson, W. S., Azhar, F., Kudela, P., Bergey, G. K. \& Franaszczuk, P. J. Epileptic seizures from abnormal networks: Why some seizures defy predictability. Epilepsy Res. 99, 202-213, (2012).

190 Baier, G., Goodfellow, M., Taylor, P. N., Wang, Y. J. \& Garry, D. J. The importance of modeling epileptic seizure dynamics as spatio-temporal patterns. Front. Physiol. 3, 281, (2012). 
191 Ansmann, G., Karnatak, R., Lehnertz, K. \& Feudel, U. Extreme events in excitable systems and mechanisms of their generation. Phys. Rev. E Stat. Nonlin. Soft Matter Phys. 88, 052911, (2013).

192 Petkov, G., Goodfellow, M., Richardson, M. P. \& Terry, J. R. A critical role for network structure in seizure onset: a computational modeling approach. Front. Neurol. 5, 261, (2014).

193 Ansmann, G., Lehnertz, K. \& Feudel, U. Self-induced pattern switching on complex networks of excitable units. Phys. Rev. X 6, 011030, (2016).

194 Schiff, S. J. Neural control engineering: the emerging intersection between control theory and neuroscience. (MIT Press, 2012).

195 Chong, M. S., Nešić, D., Postoyan, R. \& Kuhlmann, L. Parameter and state estimation of nonlinear systems using a multi-observer under the supervisory framework. IEEE

Transactions on Automatic Control 60, 2336-2349, (2015).

196 Kuhlmann, L. et al. Neural mass model-based tracking of anesthetic brain states. Neuroimage 133, 438-456, (2016).

197 Xian, L., Qing, G. \& Xiao-Li, L. Control of epileptiform spikes based on nonlinear unscented Kalman filter. Chinese Physics B 23, 010202, (2013).

198 Taylor, P. N. et al. Optimal control based seizure abatement using patient derived connectivity. Front. Neurosci. 9, 202, (2015).

199 Wei, Y., Ullah, G. \& Schiff, S. J. Unification of neuronal spikes, seizures, and spreading depression. J. Neurosci. 34, 11733-11743, (2014).

200 De Ciantis, A. \& Lemieux, L. Localisation of epileptic foci using novel imaging modalities. Curr. Opin. Neurol. 26, 368-373, (2013).

201 Krook-Magnuson, E., Armstrong, C., Oijala, M. \& Soltesz, I. On-demand optogenetic control of spontaneous seizures in temporal lobe epilepsy. Nature communications 4, 1376, (2013).

202 Badawy, R. A., Freestone, D. R., Lai, A. \& Cook, M. J. Epilepsy: Ever-changing states of cortical excitability. Neuroscience 222, 89-99, (2012).

203 Bazaka, K. \& Jacob, M. V. Implantable devices: issues and challenges. Electronics 2, 1-34, (2012).

204 Jory, C. et al. Safe and sound? A systematic literature review of seizure detection methods for personal use. Seizure 36, 4-15, (2016).

205 Patel, A. D. et al. Patient-centered design criteria for wearable seizure detection devices. Epilepsy Behav. 64, 116-121, (2016).

206 Ramgopal, S. et al. Seizure detection, seizure prediction, and closed-loop warning systems in epilepsy. Epilepsy Behav. 37, 291-307, (2014).

207 Van de Vel, A. et al. Non-EEG seizure detection systems and potential SUDEP prevention: State of the art: Review and update. Seizure 41, 141-153, (2016).

208 Arthurs, S., Zaveri, H. P., Frei, M. G. \& Osorio, I. Patient and caregiver perspectives on seizure prediction. Epilepsy Behav. 19, 474-477, (2010).

209 Schulze-Bonhage, A. et al. Views of patients with epilepsy on seizure prediction devices. Epilepsy Behav. 18, 388-396, (2010).

210 Hoppe, C. et al. Novel techniques for automated seizure registration: Patients' wants and needs. Epilepsy Behav. 52, 1-7, (2015).

211 Hoppe, C., Poepel, A. \& Elger, C. E. Epilepsy: accuracy of patient seizure counts. Arch. Neurol. 64, 1595-1599, (2007).

212 Blachut, B. et al. Counting seizures: The primary outcome measure in epileptology from the patients' perspective. Seizure 29, 97-103, (2015).

213 Elger, C. E. \& Hoppe, C. Diagnostic challenges in epilepsy: seizure under-reporting and seizure detection. Lancet Neurol. 17, 279-288, (2018).

214 Johansson, D., Malmgren, K. \& Murphy, M. A. Wearable sensors for clinical applications in epilepsy, Parkinson's disease, and stroke: a mixed-methods systematic review. J. Neurol., 1-13, (2018).

215 Vandecasteele, K. et al. Automated Epileptic Seizure Detection Based on Wearable ECG and PPG in a Hospital Environment. Sensors (Basel) 17, 2338, (2017).

216 Gadhoumi, K., Lina, J. M., Mormann, F. \& Gotman, J. Seizure prediction for therapeutic devices: A review. J. Neurosci. Methods 260, 270-282, (2016). 
217 Fisher, R. et al. Electrical stimulation of the anterior nucleus of thalamus for treatment of refractory epilepsy. Epilepsia 51, 899-908, (2010).

218 Sun, F. T. \& Morrell, M. J. The RNS System: responsive cortical stimulation for the treatment of refractory partial epilepsy. Expert Rev. Med. Devices 11, 563-572, (2014).

219 Yuan, H. \& Silberstein, S. D. Vagus Nerve and Vagus Nerve Stimulation, a Comprehensive Review: Part II. Headache 56, 259-266, (2016).

220 Duun-Henriksen, J. et al. Subdural to subgaleal EEG signal transmission: the role of distance, leakage and insulating affectors. Clin. Neurophysiol. 124, 1570-1577, (2013).

221 Stacey, W. C. \& Litt, B. Technology insight: neuroengineering and epilepsy-designing devices for seizure control. Nature Clinical Practice Neurology 4, 190-201, (2008).

222 Brinkmann, B. H. et al. Forecasting Seizures Using Intracranial EEG Measures and SVM in Naturally Occurring Canine Epilepsy. PLoS One 10, e0133900, (2015). 


\section{Brain \& Body}

e.g. local or large cortical regions,

deep brain,

hippocampus

\section{Raw Data}

e.g. intracranial

EEG, scalp EEG,

microelectrode

recordings, ECG, NIRS

\section{Seizure Prediction System}

Preprocessing
e.g. artefact
removal, signal re-
referencing

\section{Characteristics} Extraction

e.g. frequency-band power, synchrony, model parameters

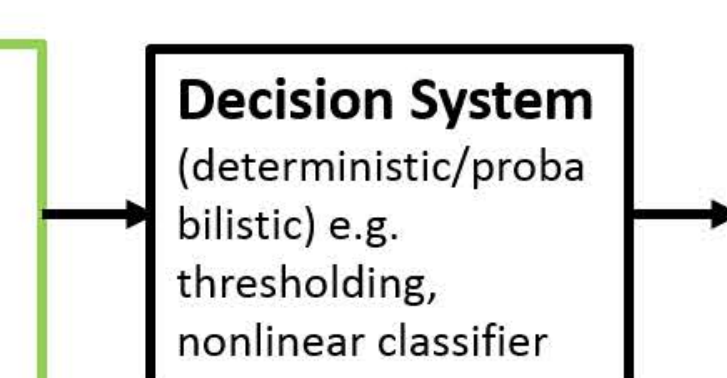

nonlinear classifier

\section{Warning/}

Advisory System

(discrete/graded) e.g.

flashing light on

external device

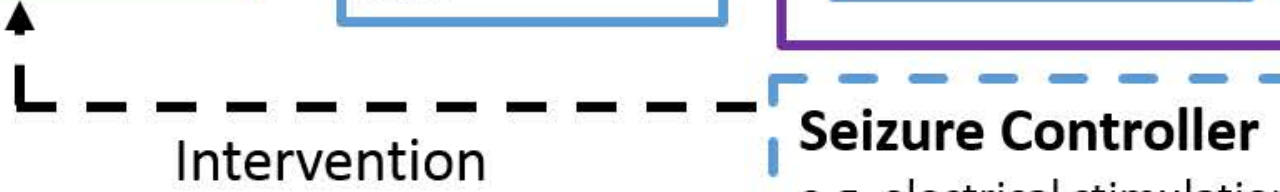

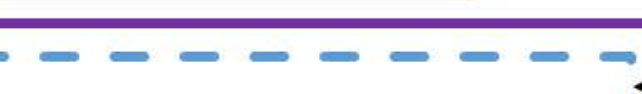

$--------$

e.g. electrical stimulation, drug delivery, cooling Warning signal

\section{B Ambulatory Seizure Advisory System}

Implantable

Electrode Leads

Implantable

Telemetry Unit

Personal

Advisory

Device

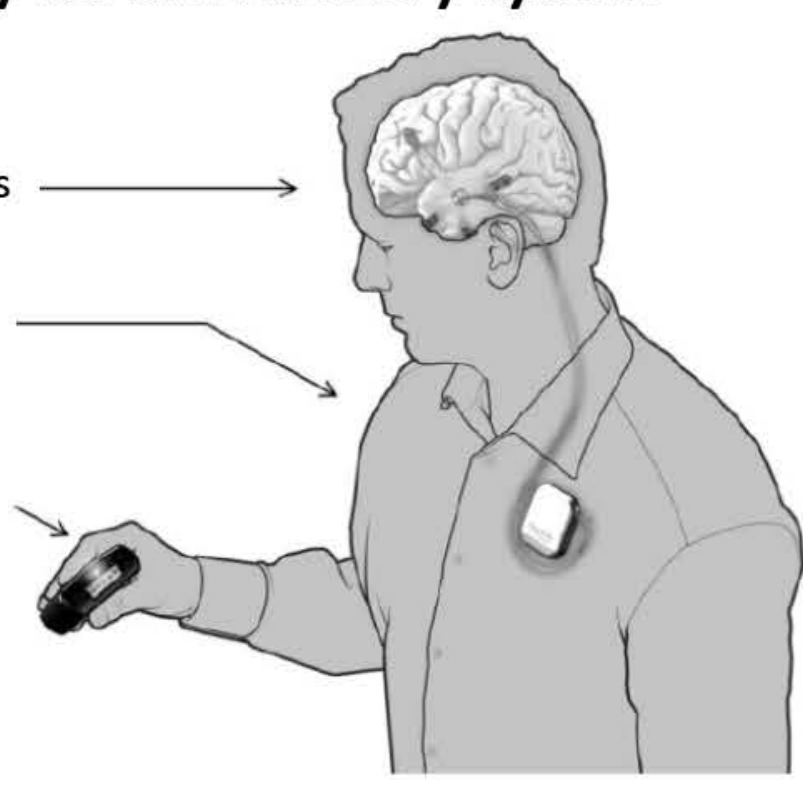

C

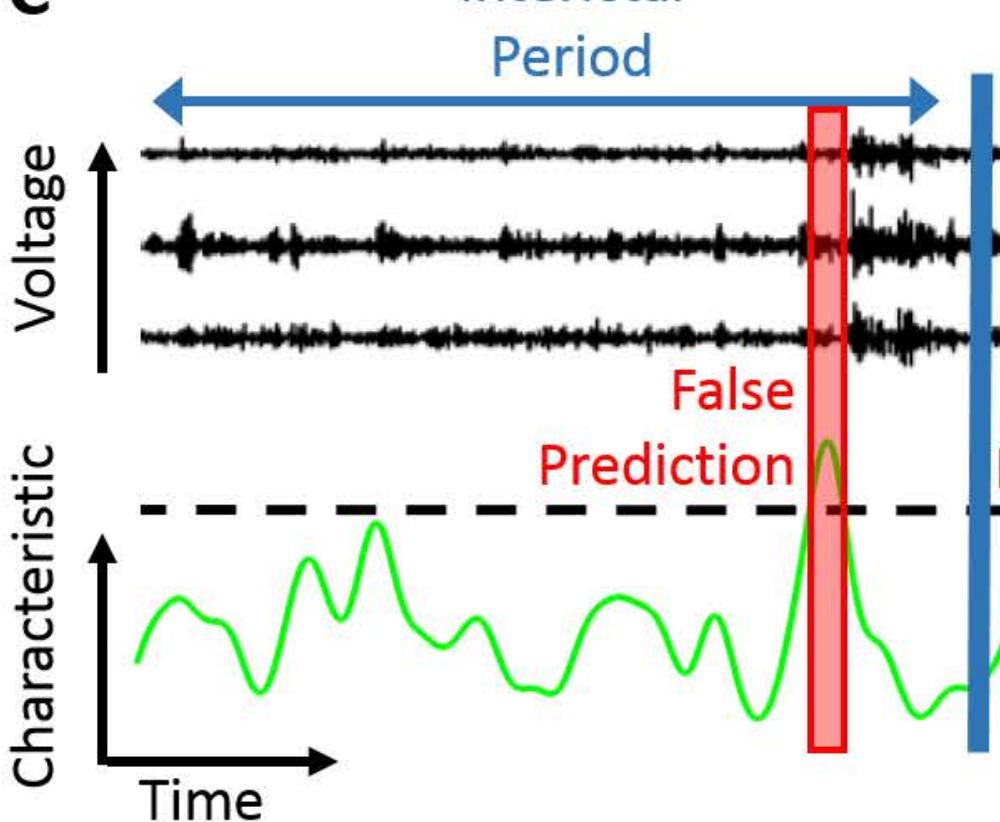

Seizure

Onset

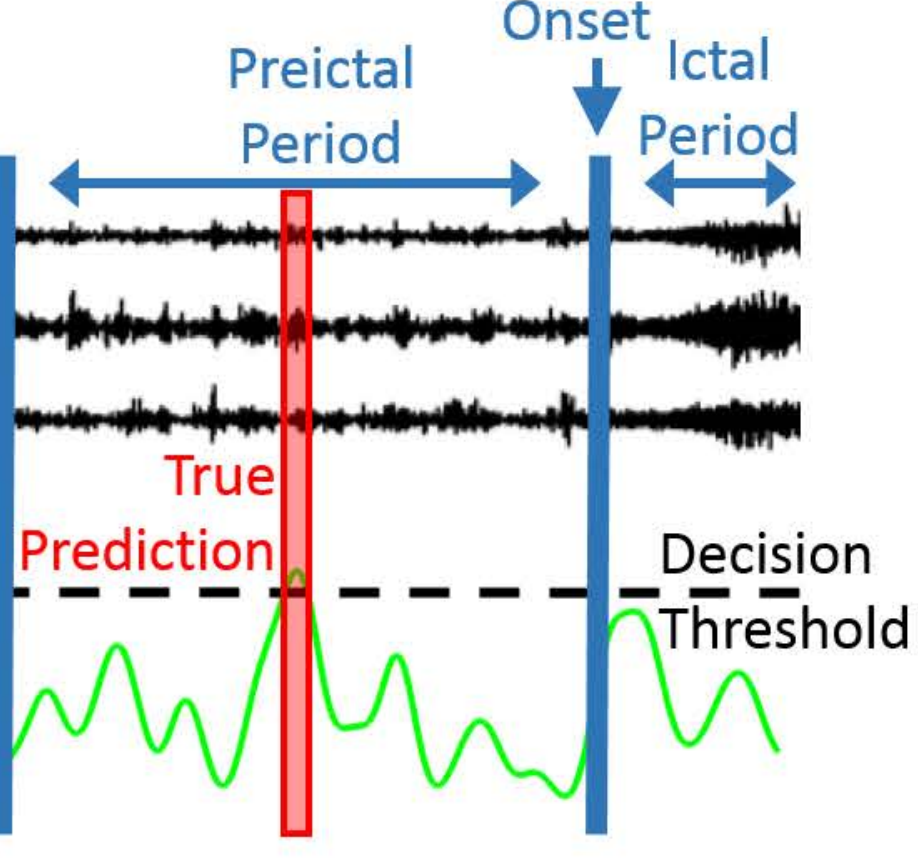




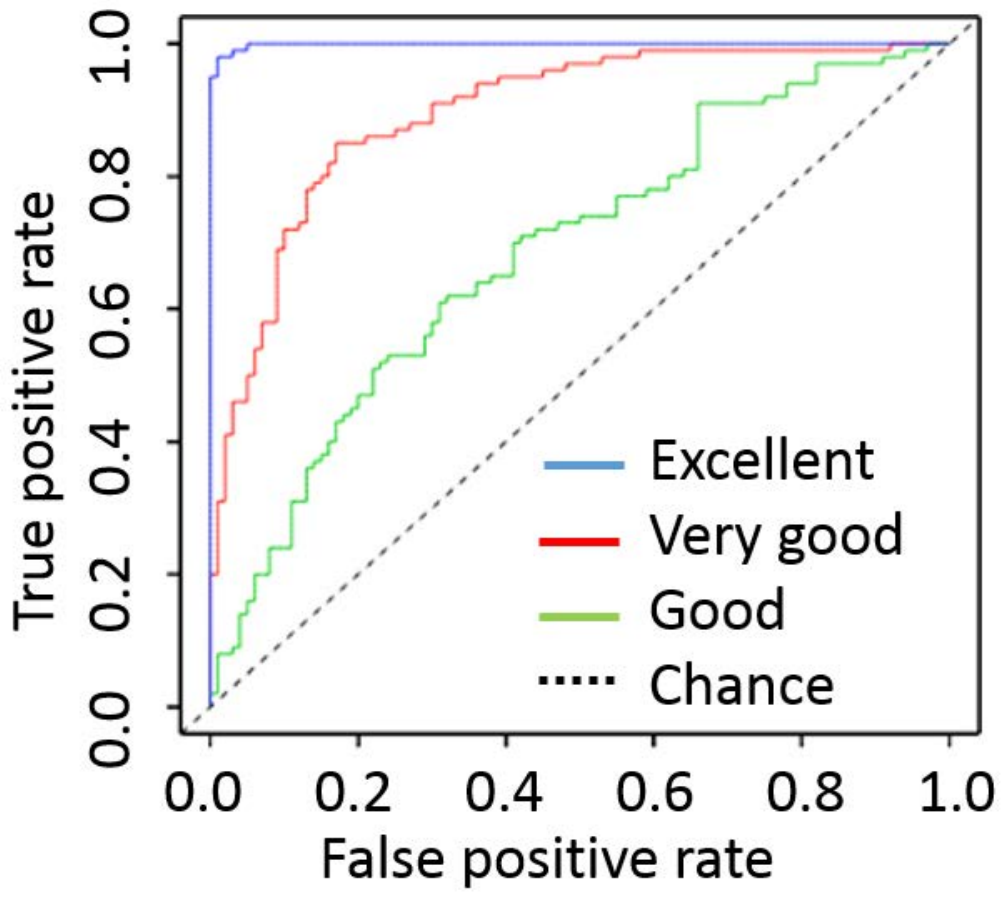


Supplementary information box 1 | Critical discussion of seizure prediction studies since 2007 .

In the landmark review of seizure prediction published in $2007^{1}$, seizure prediction algorithms from the preceding 10 years were summarized in tables. We now present a similar set of tables for seizure prediction algorithms published between 2006 and 2018 (Supplementary table 1 and Supplementary table 2$)^{2}$.

The studies listed should not be considered exhaustive. Papers were selected on the basis of adherence to the guidelines in the 2007 review, and those that included the most data were preferred for inclusion. The guidelines called for: data that are as continuous as possible; prediction algorithm performance that outperforms random prediction, surrogate methods or other algorithms that have been shown to outperform random prediction or surrogate methods; evaluation of performance on out-of-sample (but within individual) testing sets; and no in-sample parameter optimization or retrospective best channel selection (that is, parameter optimization should only be performed on the training set). .

The algorithms and their performance are listed in supplementary tables 1 and 2 on the basis of whether the study was prospective or not (pseudo-prospective evaluation was not considered prospective), then in approximate decreasing order of the size of the database or data set used, determined by the number of seizures per individual and, where these numbers are similar, the number of hours of recorded electroencephalography (EEG) or intracranial EEG data per individual. The methods have been listed in this order because of the importance of prospective studies and because, as has been considered in depth in the literature ${ }^{1}$, the ability to properly evaluate seizure prediction methods depends on the number of seizures and the duration of the (notably inter-ictal) data analysed for each individual. Another important factor in each study is the number of individuals considered, as seizure prediction results should ideally be generally applicable to many individuals.

Considerable differences still exist in the way investigators describe the performance and properties of a prediction system. Typically, one or more of the following metrics are adopted: sensitivity (the percentage of correctly predicted seizures), false prediction rate (preferably evaluated with respect to the inter-ictal periods and not including the pre-ictal periods), warning time portion the percentage of time spent under warning or false warning, assumed pre-ictal period (the time before seizure onset within which pre-ictal changes are assumed to occur), and prediction time (the time relative to seizure onset at which a prediction is made). For these metrics, ranges of values or averages have been reported in different studies. Ranges are important because some prediction algorithms work for some people but not for others. Of note, the clinical trial of the prospective seizure prediction system ${ }^{2}$ effectively reported time under warning, whereas in many other studies, time under false warning has been reported.

Since 2007, a wide variety of algorithms have been applied across various data sets, and use of smaller data sets has generally produced better algorithm performance (higher sensitivity and lower false positive rates and/or warning time portions). This observation can probably be attributed to the limited number of seizures, the limited amount of inter-ictal data and, potentially, discontinuity of data within these data sets. Therefore, algorithms that have been evaluated with the smaller data sets will need to be evaluated with larger datasets for conclusions to be made. Moreover, the performances of many algorithms published since 2007 must be interpreted with great care, particularly for those used with the FSPEEG database given that only parts of the database have been analysed in some studies and different segments of the data have been analysed in different ways (for example, in contiguous blocks or short interleaved windows) in others. Moreover, high discrimination between pre-ictal and inter-ictal data from the FSPEEG database has been reported in many studies, but might be due to a data selection bias that has been documented before ${ }^{3}$. Nevertheless, successful prospective seizure prediction for some individuals and not for others in the clinical trial of a prospective seizure prediction system suggests considerable opportunities to assess whether several of the algorithms can improve prospective seizure prediction in long-term recordings. For example, if improvements in seizure 
prediction can be achieved for individuals in whom seizure prediction was poorest with the prospective seizure prediction system ${ }^{2}$, such improvements could justify a larger scale trial in a wider range of patients ${ }^{4}$.

1 Mormann, F., Andrzejak, R. G., Elger, C. E. \& Lehnertz, K. Seizure prediction: the long and winding road. Brain 130, 314-333, doi:10.1093/brain/awl241 (2007).

2 Cook, M. J. et al. Prediction of seizure likelihood with a long-term, implanted seizure advisory system in patients with drug-resistant epilepsy: a first-in-man study. Lancet Neurol 12, 563-571 (2013).

3 Czarnek, N., Morton, K., Collins, L., Tantum, S. \& Throckmorton, C. The impact of time on seizure prediction performance in the FSPEEG database. Epilepsy Behav 48, 79-82 (2015).

4 Kuhlmann, L. et al. Epilepsyecosystem.org: Crowd-Sourcing Reproducible Seizure Prediction with Long-Term Human Intracranial EEG. Brain In Press (2018). 
Supplementary table 1 | Human seizure prediction studies from 2006 to 2018 involving (semi-)continuous data.

\begin{tabular}{|c|c|c|c|c|c|c|c|c|c|}
\hline Year & Ref. & Predictive characteristic & $\begin{array}{l}\text { Pre-ictal change } \\
\text { detection } \\
\text { method }\end{array}$ & $\begin{array}{l}\text { EEG } \\
\text { type }\end{array}$ & $\begin{array}{l}\text { Epileps } \\
\text { y } \\
\text { type }\end{array}$ & $\begin{array}{l}\text { No. of } \\
\text { patients }\end{array}$ & $\begin{array}{l}\text { Seizure } \\
\text { s per } \\
\text { patient }\end{array}$ & $\begin{array}{l}\text { EEG } \\
\text { time } \\
\text { (h per } \\
\text { patient) }\end{array}$ & Prospective? \\
\hline \multicolumn{10}{|c|}{ Clinical trial database } \\
\hline $\begin{array}{l}201 \\
3\end{array}$ & & $\begin{array}{l}\text { Average/Teager-Kaiser } \\
\text { energy, line length }\end{array}$ & $\begin{array}{l}\text { Decision tree, } \\
\text { kNN, state } \\
\text { machine }\end{array}$ & iEEG & RFE & $11^{\mathrm{a}}$ & 81.7 & 6956.3 & $\mathrm{Y}$ \\
\hline $\begin{array}{l}201 \\
8\end{array}$ & 2 & Spectrograms & $\begin{array}{l}\text { Deep learning } \\
\text { CNN }\end{array}$ & iEEG & RFE & 10 & 281.7 & 14270.0 & $\mathrm{~N}$ \\
\hline $\begin{array}{l}201 \\
7\end{array}$ & 3 & Spectral energy, line-length & $\begin{array}{l}\text { Circadian- } \\
\text { weighted logistic } \\
\text { regression }\end{array}$ & iEEG & RFE & 9 & 224.8 & 7677.3 & $\mathrm{~N}$ \\
\hline $\begin{array}{l}201 \\
8\end{array}$ & 4 & Numerous features & $\begin{array}{l}\text { Numerous } \\
\text { algorithms }\end{array}$ & iEEG & RFE & 3 & 211 & 3699 & $\mathrm{~N}$ \\
\hline \multicolumn{10}{|c|}{ Freiburg database } \\
\hline $\begin{array}{l}201 \\
0\end{array}$ & 5 & $\begin{array}{l}\text { Mean phase coherence, } \\
\text { dynamical similarity index }\end{array}$ & $\begin{array}{l}\text { AND operation, } \\
\text { threshold }\end{array}$ & iEEG & RFE & 8 & 19.1 & 182 & $\mathrm{~N}$ \\
\hline \multicolumn{10}{|c|}{ New Brunswick database } \\
\hline $\begin{array}{l}201 \\
3\end{array}$ & 6 & Lyapunov exponent & $\mathrm{kNN}$ & iEEG & RFE & 10 & 15.5 & 205.2 & $\mathrm{~N}$ \\
\hline $\begin{array}{l}201 \\
7\end{array}$ & 7 & $\begin{array}{l}\text { Lyapunov exponent, } 3 \\
\text { bivariate \& } 2^{\text {nd-level }} \\
\text { features }\end{array}$ & APP, ALP, ANP & iEEG & RFE & 10 & 15.4 & 206.9 & $\mathrm{~N}$ \\
\hline \multicolumn{10}{|c|}{ Gainsville database } \\
\hline $\begin{array}{l}200 \\
6\end{array}$ & 8 & Lyapunov exponent & Dynamic threshold & iEEG & MTLE & 10 & 13 & 210 & $\mathrm{~N}$ \\
\hline \multicolumn{10}{|c|}{ Freiburg contest/Melbourne database } \\
\hline $\begin{array}{l}201 \\
0\end{array}$ & 9 & mean phase coherence & $\begin{array}{l}\text { Fixed/dynamic } \\
\text { threshold }\end{array}$ & iEEG & RFE & 6 & 12.2 & 99.6 & $\mathrm{~N}$ \\
\hline \multicolumn{10}{|c|}{ EPILEPSIAE database } \\
\hline $\begin{array}{l}201 \\
4\end{array}$ & 10 & cross-frequency coupling & Threshold & iEEG & RFE & 53 & 10.5 & 240.5 & $\mathrm{~N}$ \\
\hline $\begin{array}{l}201 \\
4\end{array}$ & 11 & 22 univariate features & $\begin{array}{l}\text { SVM, RBF-NN, } \\
\text { RBP-NN }\end{array}$ & $\begin{array}{l}\text { iEEG/E } \\
\text { EG }\end{array}$ & RFE & $278^{b}$ & 9.7 & 175.3 & $\mathrm{~N}$ \\
\hline $\begin{array}{l}201 \\
2\end{array}$ & 12 & 34 algorithmic features & SVM & $\begin{array}{l}\text { iEEG/E } \\
\text { EG/ } \\
\text { ECG }\end{array}$ & RFE & $12^{\mathrm{c}}$ & 9 & 264.8 & $\mathrm{~N}$ \\
\hline $\begin{array}{l}201 \\
5\end{array}$ & 13 & $\begin{array}{l}\text { Differences/ratios of linear } \\
\text { univariate features }\end{array}$ & SVM & $\begin{array}{l}\text { iEEG/E } \\
\text { EG }\end{array}$ & RFE & $10^{d}$ & 8.6 & 138.8 & $\mathrm{~N}$ \\
\hline $\begin{array}{l}201 \\
3\end{array}$ & 14 & 22 univariate features & SVM & $\begin{array}{l}\text { iEEG/E } \\
\text { EG }\end{array}$ & RFE & $10^{d}$ & 8.6 & 138.8 & $\mathrm{~N}$ \\
\hline $\begin{array}{l}201 \\
5\end{array}$ & 15 & Bivariate spectral power & SVM & $\begin{array}{l}\mathrm{iEEG} / \mathrm{E} \\
\mathrm{EG}\end{array}$ & RFE & $24 \mathrm{e}$ & 7.6 & 148.5 & $\mathrm{~N}$ \\
\hline $\begin{array}{l}201 \\
7\end{array}$ & 16 & 22 univariate features & Multiclass SVM & $\begin{array}{l}\mathrm{iEEG} / \mathrm{E} \\
\mathrm{EG}\end{array}$ & RFE & $216^{f}$ & 5.6 & 77.5 & $\mathrm{~N}$ \\
\hline \multicolumn{10}{|c|}{ Montreal database } \\
\hline $\begin{array}{l}201 \\
5\end{array}$ & 17 & $\begin{array}{l}\text { (Scaling) cumulant, state } \\
\text { similarity }\end{array}$ & Linear discriminant & iEEG & MTLE & 17 & 10.3 & 92.1 & $\mathrm{~N}$ \\
\hline $\begin{array}{l}201 \\
3\end{array}$ & 18 & $\begin{array}{l}\text { Wavelet energy/entropy- } \\
\text { based state similarity }\end{array}$ & Linear discriminant & iEEG & MTLE & 17 & 10.3 & 92.1 & $\mathrm{~N}$ \\
\hline \multicolumn{10}{|c|}{ Bonn database } \\
\hline $\begin{array}{l}201 \\
6\end{array}$ & 19 & $\begin{array}{l}\text { Eigenvalue PCA, } \\
\text { CNN/linear prediction error, } \\
\text { crossing levels }\end{array}$ & Threshold & iEEG & RFE & 20 & 5.2 & $65-575$ & $\mathrm{~N}$ \\
\hline \multicolumn{10}{|c|}{ FSPEEG database } \\
\hline $\begin{array}{l}201 \\
4\end{array}$ & 20 & $\begin{array}{l}\text { Hilbert-Huang mean phase } \\
\text { coherence }\end{array}$ & Threshold & iEEG & RFE & 10 & 5 & $\approx 27.1$ & $\mathrm{~N}$ \\
\hline $\begin{array}{l}201 \\
2\end{array}$ & 21 & 6 nonlinear features & Rule-based & iEEG & RFE & 11 & 4.5 & $\approx 28.7$ & $\mathrm{~N}$ \\
\hline $\begin{array}{l}201 \\
1\end{array}$ & 22 & Univariate spectral power & $\begin{array}{l}\text { Cost-sensitive } \\
\text { SVM }\end{array}$ & iEEG & RFE & 18 & 4.4 & $\approx 28.5$ & $\mathrm{~N}$ \\
\hline $\begin{array}{l}201 \\
2\end{array}$ & 23 & $\begin{array}{l}\text { Univariate/multivariate } \\
\text { correlaton }\end{array}$ & SVM & iEEG & RFE & 19 & 4.4 & $\approx 28.0$ & $\mathrm{~N}$ \\
\hline $\begin{array}{l}201 \\
5\end{array}$ & 24 & $\begin{array}{l}44 \text { spectral power } \\
\text { features/ratios }\end{array}$ & Linear SVM & iEEG & RFE & 18 & 4.4 & 23.7 & $\mathrm{~N}$ \\
\hline $\begin{array}{l}200 \\
9\end{array}$ & 25 & $\begin{array}{l}6 \text { linear/nonlinear } \\
\text { synchrony }\end{array}$ & $\begin{array}{l}\text { Logistic } \\
\text { regression, CNN, } \\
\text { SVM }\end{array}$ & iEEG & RFE & 21 & 4.2 & 27.7 & $\mathrm{~N}$ \\
\hline $\begin{array}{l}201 \\
4\end{array}$ & 26 & 34 Univariate features & Voting SVM & IEEG & RFE & 21 & 4.2 & $\approx 4.2$ & $\mathrm{~N}$ \\
\hline $\begin{array}{l}201 \\
4 \\
\end{array}$ & 27 & N-gram EEG patterns & $\begin{array}{l}\text { Fixed/dynamic } \\
\text { threshold }\end{array}$ & IEEG & RFE & 21 & 4.1 & 27.7 & $N$ \\
\hline
\end{tabular}




\begin{tabular}{|c|c|c|c|c|c|c|c|c|c|}
\hline $\begin{array}{l}201 \\
4\end{array}$ & 28 & $\begin{array}{l}\text { Neural mass model } \\
\text { parameters }\end{array}$ & Rule-based & iEEG & RFE & 21 & 4.1 & 27.7 & $\mathrm{~N}$ \\
\hline $\begin{array}{l}201 \\
3\end{array}$ & 29 & Epileptic spike rate & Threshold & iEEG & RFE & 21 & 4.1 & 27.7 & $\mathrm{~N}$ \\
\hline \multicolumn{10}{|c|}{ MIT database } \\
\hline $\begin{array}{l}201 \\
5\end{array}$ & 30 & $\begin{array}{l}44 \text { spectral power } \\
\text { features/ratios }\end{array}$ & Linear SVM & EEG & $\mathrm{PE}$ & 17 & 4.6 & 38.1 & $\mathrm{~N}$ \\
\hline \multicolumn{10}{|c|}{ Vancouver/MIT database } \\
\hline $\begin{array}{l}201 \\
3\end{array}$ & 31 & Zero-crossing intervals & GMM/threshold & EEG & $\begin{array}{l}\text { TLE,eTL } \\
\mathrm{E}, \\
\mathrm{PE}\end{array}$ & 20 & 4.3 & 28.1 & $\mathrm{~N}$ \\
\hline \multicolumn{10}{|c|}{ Pittsburgh/Charleston database } \\
\hline $\begin{array}{l}201 \\
1\end{array}$ & 32 & Regularity statistic & Dynamic threshold & EEG & RFE & 52 & 2.0 & 36.06 & $\bar{N}$ \\
\hline
\end{tabular}

Databases and studies are listed in decreasing order of prospective nature, number of seizures per individual, and amount of data per individual. aTraining sets: 27.5 seizures and 4076.3 hours per individual, Testing sets: 54.3 seizures and approx. 2880 hours per individual. b42 individuals had iEEG with 253 hours per individual. 227 individuals had EEG with 162 hours per individual. cOnly 6 individuals had iEEG data. 2 individuals had iEEG data. e8 individuals had iEEG with 9.9 seizures and 175.2 hours per individual. iEEG and EEG performance were similar. ${ }^{f} 185$ individuals with EEG and 31 individuals with iEEG. ALP: adaptive linear-discriminant-analysisbased prediction; ANP: adaptive Naïve Bayes-based prediction; APP, adaptive probabilistic prediction; CNN, convolutional neural networks; ECG, electrocardiogram; EEG, electroencephalography, eTLE, extra-TLE; GMM, Gaussian mixture model;, iEEG, intracranial EEG; kNN, k-nearest neighbours; MTLE, medial LTE; NFE, natural focal epilepsy; PE, paediatric epilepsy; RBF-NN, radial basis function neural networks; RBP-NN, resilient backpropagation neural networks; RFE, refractory focal epilepsy; SVM, support vector machine; TLE, temporal lobe epilepsy.

1 Cook, M. J. et al. Prediction of seizure likelihood with a long-term, implanted seizure advisory system in patients with drug-resistant epilepsy: a first-in-man study. Lancet Neurol. 12, 563-571, (2013).

2 Kiral-Kornek, I. et al. Epileptic Seizure Prediction Using Big Data and Deep Learning: Toward a Mobile System. Ebiomedicine 27, 103-111, (2018).

3 Karoly, P. J. et al. The circadian profile of epilepsy improves seizure forecasting. Brain 140, 2169-2182, (2017).

$4 \quad$ Kuhlmann, L. et al. Epilepsyecosystem.org: Crowd-Sourcing Reproducible Seizure Prediction with Long-Term Human Intracranial EEG. Brain, In Press, (2018).

5 Feldwisch-Drentrup, $\mathrm{H}$. et al. Joining the benefits: combining epileptic seizure prediction methods. Epilepsia 51, 1598-1606, (2010).

6 Wang, S., Chaovalitwongse, W. A. \& Wong, S. Online seizure prediction using an adaptive learning approach. IEEE Trans, Know. Data Eng. 25, 2854-2866, (2013).

$7 \quad$ Xiao, C., Wang, S., lasemidis, L., Wong, S. \& Chaovalitwongse, W. A. An Adaptive Pattern Learning Framework to Personalize Online Seizure Prediction. IEEE Trans. Big Data DOI: 10.1109/tbdata.2017.2675982, (2017).

8 Sackellares, J. C. et al. Predictability analysis for an automated seizure prediction algorithm. Journal of Clin. Neurophysiol. 23, 509-520, (2006).

9 Kuhlmann, L. et al. Patient-specific bivariate-synchrony-based seizure prediction for short prediction horizons. Epilepsy Res. 91, 214-231, (2010).

10 Alvarado-Rojas, C. et al. Slow modulations of high-frequency activity $(40-140-\mathrm{Hz})$ discriminate preictal changes in human focal epilepsy. Sci. Rep. 4, 4545, (2014).

11 Teixeira, C. A. et al. Epileptic seizure predictors based on computational intelligence techniques: A comparative study with 278 patients. Comput. Methods Programs Biomed. 114, 324-336, (2014).

12 Valderrama, M. et al. Identifying an increased risk of epileptic seizures using a multi-feature EEG-ECG classification. Biomed. Sig. Proc. Control 7, 237-244, (2012).

13 Rasekhi, J., Mollaei, M. R. K., Bandarabadi, M., Teixeira, C. A. \& Dourado, A. Epileptic seizure prediction based on ratio and differential linear univariate features. J.Med. Sig. Sens. 5, 1, (2015).

14 Rasekhi, J., Mollaei, M. R. K., Bandarabadi, M., Teixeira, C. A. \& Dourado, A. Preprocessing effects of 22 linear univariate features on the performance of seizure prediction methods. J. Neurosci. Methods 217, 9-16, (2013).

15 Bandarabadi, M., Teixeira, C. A., Rasekhi, J. \& Dourado, A. Epileptic seizure prediction using relative spectral power features. Clin. Neurophysiol. 126, 237-248, (2015).

16 Direito, B., Teixeira, C. A., Sales, F., Castelo-Branco, M. \& Dourado, A. A Realistic Seizure Prediction Study Based on Multiclass SVM. Int. J. Neural Syst. 27, 1750006, (2017). 

improve seizure prediction in mesial temporal lobe epilepsy. PLoS One 10, e0121182, (2015).

18 Gadhoumi, K., Lina, J. M. \& Gotman, J. Seizure prediction in patients with mesial temporal lobe epilepsy using EEG measures of state similarity. Clin. Neurophysiol. 124, 1745-1754, (2013).

19 Senger, V. \& Tetzlaff, R. New Signal Processing Methods for the Development of Seizure Warning Devices in Epilepsy. IEEE Transactions. on Circuits and Systems I: Regular Papers 63, 609-616, (2016).

20 Zheng, Y., Wang, G., Li, K., Bao, G. \& Wang, J. Epileptic seizure prediction using phase synchronization based on bivariate empirical mode decomposition. Clin. Neurophysiol. 125, 1104-1111, (2014).

21 Aarabi, A. \& He, B. A rule-based seizure prediction method for focal neocortical epilepsy. Clin. Neurophysiol. 123, 1111-1122, (2012).

22 Park, Y., Luo, L., Parhi, K. K. \& Netoff, T. Seizure prediction with spectral power of EEG using cost-sensitive support vector machines. Epilepsia 52, 1761-1770, (2011).

23 Williamson, J. R., Bliss, D. W., Browne, D. W. \& Narayanan, J. T. Seizure prediction using EEG spatiotemporal correlation structure. Epilepsy Behav. 25, 230-238, (2012).

24 Zhang, Z. \& Parhi, K. K. Low-Complexity Seizure Prediction From iEEG/sEEG Using Spectral Power and Ratios of Spectral Power. IEEE Trans. Biomed. Circ. Syst. 10, 693706, (2015).

25 Mirowski, P., Madhavan, D., Lecun, Y. \& Kuzniecky, R. Classification of patterns of EEG synchronization for seizure prediction. Clin. Neurophysiol. 120, 1927-1940, (2009).

26 Moghim, N. \& Corne, D. W. Predicting epileptic seizures in advance. PloS one 9, e99334, (2014).

27 Eftekhar, A., Juffali, W., El-Imad, J., Constandinou, T. G. \& Toumazou, C. Ngram-derived pattern recognition for the detection and prediction of epileptic seizures. PloS one $\mathbf{9}$, e96235, (2014).

28 Aarabi, A. \& He, B. Seizure prediction in hippocampal and neocortical epilepsy using a model-based approach. Clin. Neurophysiol. 125, 930-940, (2014).

29 Li, S. F., Zhou, W. D., Yuan, Q. \& Liu, Y. X. Seizure Prediction Using Spike Rate of Intracranial EEG. IEEE Transactions on Neural Systems and Rehabilitation Engineering 21, 880-886, (2013).

30 Zhang, Z. \& Parhi, K. K. in 37th Annual International Conference of the IEEE Engineering in Medicine and Biology Society (EMBC). (IEEE. p. 5748-5751).

31 Zandi, A. S., Tafreshi, R., Javidan, M. \& Dumont, G. A. Predicting epileptic seizures in scalp EEG based on a variational Bayesian Gaussian mixture model of zero-crossing intervals. IEEE Trans. Biomed. Eng. 60, 1401-1413, (2013).

32 Chien, J.-H. et al. A signal regularity-based automated seizure prediction algorithm using long-term scalp EEG recordings. Cybern. Syst. Anal. 47, 586-597, (2011). 
Supplementary table 2 | Performance information for human seizure prediction studies from 2006 to 2018.

\begin{tabular}{|c|c|c|c|c|c|c|c|c|c|c|}
\hline Year & $\begin{array}{l}\text { Ref } \\
\text {. }\end{array}$ & $\begin{array}{l}\text { In-sample } \\
\text { parameter } \\
\text { optimizatio } \\
\mathrm{n}\end{array}$ & $\begin{array}{l}\text { Retrosp } \\
\text { ective } \\
\text { best } \\
\text { channel } \\
\text { selectio } \\
\text { n }\end{array}$ & $\begin{array}{l}\text { Out-of- } \\
\text { sampl } \\
\text { e } \\
\text { testing }\end{array}$ & $\begin{array}{l}\text { Sensitivit } \\
\text { y } \\
\text { (\%) }\end{array}$ & $\begin{array}{l}\text { False- } \\
\text { positives } \\
\text { per hour }\end{array}$ & $\begin{array}{l}\text { Warnin } \\
\text { g } \\
\text { time } \\
\text { portion } \\
(\%)\end{array}$ & $\begin{array}{l}\text { Assumed } \\
\text { pre-ictal } \\
\text { period } \\
(\mathrm{min})\end{array}$ & $\begin{array}{l}\text { Predictio } \\
\text { n } \\
\text { time }(\min )\end{array}$ & $\begin{array}{l}\text { Statistical } \\
\text { validation } \\
\text { method }\end{array}$ \\
\hline \multicolumn{11}{|c|}{ Clinical trial database } \\
\hline 2013 & 1 & $\mathrm{~N}$ & $\mathrm{~N}$ & $\mathrm{Y}$ & $54-100$ & $\mathrm{n} / \mathrm{a}$ & $3-41$ & $\mathrm{n} / \mathrm{a}$ & 114 & $\begin{array}{l}\text { Random } \\
\text { Poisson }\end{array}$ \\
\hline 2018 & 2 & $\mathrm{~N}$ & $\mathrm{~N}$ & $\mathrm{Y}$ & 69 & $\mathrm{n} / \mathrm{a}$ & 27 & $\mathrm{n} / \mathrm{a}$ & $<60$ & $\begin{array}{l}\text { Random } \\
\text { Poisson }\end{array}$ \\
\hline 2017 & $\overline{3}$ & $\mathrm{~N}$ & $\mathrm{~N}$ & $\mathrm{Y}$ & $45-78$ & $\mathrm{n} / \mathrm{a}$ & $12-41$ & $30-60$ & $\mathrm{n} / \mathrm{a}$ & $\begin{array}{l}\text { Random } \\
\text { Poisson }\end{array}$ \\
\hline 2018 & 4 & $\mathrm{~N}$ & $\mathrm{~N}$ & $\mathrm{Y}$ & $50-60$ & $\mathrm{n} / \mathrm{a}$ & $10-30$ & 60 & $\mathrm{n} / \mathrm{a}$ & $\begin{array}{l}\text { Random } \\
\text { Poisson }\end{array}$ \\
\hline \multicolumn{11}{|c|}{ Freiburg database } \\
\hline 2010 & 5 & $\mathrm{Y}$ & $\mathrm{N}$ & $\mathrm{Y}$ & 43.2 & 0.15 & $\mathrm{n} / \mathrm{a}$ & $10-60$ & $\mathrm{n} / \mathrm{a}$ & $\begin{array}{l}\text { Random } \\
\text { Poisson }\end{array}$ \\
\hline \multicolumn{11}{|c|}{ New Brunswick database } \\
\hline 2013 & 6 & $\mathrm{~N}$ & $\mathrm{~N}$ & $\mathrm{Y}$ & 73 & $\mathrm{n} / \mathrm{a}$ & 33 & 180 & $\mathrm{n} / \mathrm{a}$ & $\begin{array}{l}\text { Periodic or } \\
\text { random } \\
\text { Poisson }\end{array}$ \\
\hline 2017 & 7 & $\mathrm{~N}$ & $\mathrm{~N}$ & $\mathrm{Y}$ & $71-80$ & $\mathrm{n} / \mathrm{a}$ & $3-25$ & 30 & $9.3-14.3$ & $\begin{array}{l}\text { Periodic or } \\
\text { random } \\
\text { Poisson }\end{array}$ \\
\hline \multicolumn{11}{|c|}{ Gainsville database } \\
\hline 2006 & 8 & $\mathrm{Y}$ & $\mathrm{N}$ & $\mathrm{N}$ & 80 & $0.56,0.12$ & 28,32 & 30,180 & 13,90 & $\begin{array}{l}\text { Periodic or } \\
\text { random } \\
\text { Poisson }\end{array}$ \\
\hline \multicolumn{11}{|c|}{ Freiburg contest/Melbourne database } \\
\hline 2010 & 9 & $\mathrm{Y}$ & $\mathrm{Y}$ & $\mathrm{Y}$ & $50-88$ & $0.64-4.69$ & $\mathrm{n} / \mathrm{a}$ & $<15$ & $\mathrm{n} / \mathrm{a}$ & $\begin{array}{l}\text { Random } \\
\text { Poisson or } \\
\text { alarm-time } \\
\text { surrogates } \\
\end{array}$ \\
\hline \multicolumn{11}{|c|}{ EPILEPSIAE database } \\
\hline 2014 & 10 & $\mathrm{~N}$ & $\mathrm{~N}$ & $\mathrm{Y}$ & $36-100^{a}$ & $0.08-0.72^{\mathrm{a}}$ & $\mathrm{n} / \mathrm{a}$ & $30-60$ & $\mathrm{n} / \mathrm{a}$ & $\begin{array}{l}\text { Random } \\
\text { Poisson }\end{array}$ \\
\hline 2014 & 11 & $\mathrm{~N}$ & $\mathrm{~N}$ & $\mathrm{Y}$ & $>50^{\mathrm{b}}$ & $<0.15^{b}$ & $\mathrm{n} / \mathrm{a}$ & $10-40$ & $\mathrm{n} / \mathrm{a}$ & None \\
\hline 2012 & 12 & $\mathrm{~N}$ & $\mathrm{~N}$ & $\mathrm{Y}$ & $2-81$ & $\mathrm{n} / \mathrm{a}^{\mathrm{c}}$ & $\mathrm{n} / \mathrm{a}$ & $20-60$ & $\mathrm{n} / \mathrm{a}$ & $\begin{array}{l}\text { Seizure-time } \\
\text { surrogates }\end{array}$ \\
\hline 2015 & 13 & $\mathrm{~N}$ & $\mathrm{~N}$ & $\mathrm{Y}$ & 60.9 & 0.11 & $n / a$ & $10-40$ & $\mathrm{n} / \mathrm{a}$ & $\begin{array}{l}\text { Random } \\
\text { Poisson }\end{array}$ \\
\hline 2013 & 14 & $\mathrm{~N}$ & $\mathrm{~N}$ & $\mathrm{Y}$ & 73.9 & 0.15 & $\mathrm{n} / \mathrm{a}$ & $10-40$ & $\mathrm{n} / \mathrm{a}$ & None \\
\hline 2015 & 15 & $\mathrm{~N}$ & $\mathrm{~N}$ & $\mathrm{Y}$ & 75.8 & 0.1 & $\mathrm{n} / \mathrm{a}$ & 30 & $\mathrm{n} / \mathrm{a}$ & $\begin{array}{l}\text { Random } \\
\text { Poisson }\end{array}$ \\
\hline 2017 & 16 & $\mathrm{~N}$ & $\mathrm{~N}$ & $\mathrm{Y}$ & 38.5 & 0.2 & $\mathrm{n} / \mathrm{a}$ & 28 & $\mathrm{n} / \mathrm{a}$ & $\begin{array}{l}\text { Random } \\
\text { Poisson }\end{array}$ \\
\hline \multicolumn{11}{|c|}{ Montreal database } \\
\hline 2015 & 17 & $\mathrm{~N}$ & $\mathrm{~N}$ & $\mathrm{Y}$ & $80.5^{d}$ & 0.15 & 25.1 & $\mathrm{n} / \mathrm{a}$ & 59.4 & $\begin{array}{l}\text { Random } \\
\text { Poisson }\end{array}$ \\
\hline 2013 & 18 & $\mathrm{~N}$ & $\mathrm{~N}$ & $\mathrm{Y}$ & $81.4^{\mathrm{e}}$ & 0.15 & 30.5 & $\mathrm{n} / \mathrm{a}$ & 50.6 & $\begin{array}{l}\text { Random } \\
\text { Poisson }\end{array}$ \\
\hline \multicolumn{11}{|c|}{ Bonn database } \\
\hline 2016 & 19 & $\mathrm{Y}$ & $\mathrm{N}$ & $\mathrm{Y}$ & $\mathrm{n} / \mathrm{a}^{f}$ & $n / a^{f}$ & $\mathrm{n} / \mathrm{a}$ & $20-120$ & $\mathrm{n} / \mathrm{a}$ & $\begin{array}{l}\text { Seizure time } \\
\text { surrogates }\end{array}$ \\
\hline \multicolumn{11}{|c|}{ FSPEEG database } \\
\hline 2014 & 20 & $\mathrm{Y}$ & $\mathrm{Y}$ & $\mathrm{Y}$ & 70 & 0.15 & $\mathrm{n} / \mathrm{a}$ & 40 & $\mathrm{n} / \mathrm{a}$ & $\begin{array}{l}\text { Random } \\
\text { Poisson }\end{array}$ \\
\hline 2012 & 21 & $\mathrm{~N}$ & $\mathrm{~N}$ & $\mathrm{Y}$ & $79.9,90.2$ & $0.17,0.11$ & 4 & 30,50 & 13,24 & $\begin{array}{l}\text { Periodic or } \\
\text { random } \\
\text { Poisson } \\
\end{array}$ \\
\hline 2011 & 22 & $\mathrm{~N}$ & $\mathrm{~N}$ & $\bar{Y}$ & 92.5 & 0.2 & 9.5 & 30 & $\mathrm{n} / \mathrm{a}$ & $\begin{array}{l}\text { Random } \\
\text { Poisson }\end{array}$ \\
\hline 2012 & 23 & $\mathrm{~N}$ & $\mathrm{~N}$ & $\mathrm{Y}$ & 86 & 0.03 & 3 & 30 & $\mathrm{n} / \mathrm{a}$ & $\begin{array}{ll}\begin{array}{l}\text { 2-class } \\
\text { chance }\end{array} & \text { ROC } \\
\end{array}$ \\
\hline 2015 & 24 & $\mathrm{~N}$ & $\mathrm{~N}$ & $\mathrm{Y}$ & 100 & 0.03 & $n / a$ & $16-54$ & $\mathrm{n} / \mathrm{a}$ & $\begin{array}{ll}\begin{array}{l}\text { 2-class } \\
\text { chance }\end{array} & \text { ROC } \\
\end{array}$ \\
\hline 2009 & 25 & $\mathrm{~N}$ & $\mathrm{~N}$ & $\mathrm{Y}$ & 1009 & 0 & $\mathrm{n} / \mathrm{a}$ & 120 & $2-99$ & Random \\
\hline 2014 & 26 & $\mathrm{~N}$ & $\mathrm{~N}$ & $\mathrm{Y}$ & $89-93$ & $\mathrm{n} / \mathrm{a}^{h}$ & $\mathrm{n} / \mathrm{a}$ & $<20$ & $\mathrm{n} / \mathrm{a}$ & $\begin{array}{l}\text { Baseline or } \\
\text { random } \\
\text { Poisson }\end{array}$ \\
\hline 2014 & 27 & $\mathrm{~N}$ & $\mathrm{~N}$ & $\mathrm{Y}$ & $54-94$ & $0.01-0.22$ & $\mathrm{n} / \mathrm{a}$ & 20 & $\mathrm{n} / \mathrm{a}$ & $\begin{array}{l}\text { random } \\
\text { Poisson }\end{array}$ \\
\hline
\end{tabular}




\begin{tabular}{|c|c|c|c|c|c|c|c|c|c|c|}
\hline 2014 & 28 & $\mathrm{~N}$ & $\mathrm{~N}$ & $\bar{Y}$ & 83,90 & $0.16,0.12$ & 2.7 & 30,50 & $15.4,27$ & $\begin{array}{l}\text { Periodic or } \\
\text { random } \\
\text { Poisson }\end{array}$ \\
\hline 2013 & 29 & $\mathrm{~N}$ & $\mathrm{~N}$ & $\mathrm{Y}$ & 72.7 & 0.11 & $\mathrm{n} / \mathrm{a}$ & 50 & $\approx 49.7$ & Random \\
\hline \multicolumn{11}{|c|}{ MIT database } \\
\hline 2015 & 30 & $\mathrm{~N}$ & $\mathrm{~N}$ & $\bar{Y}$ & 98.7 & 0.05 & $\mathrm{n} / \mathrm{a}$ & $3-78$ & $\mathrm{n} / \mathrm{a}$ & $\begin{array}{ll}\begin{array}{l}\text { 2-class } \\
\text { chance }\end{array} & \text { ROC }\end{array}$ \\
\hline \multicolumn{11}{|c|}{ Vancouver/MIT database } \\
\hline 2013 & 31 & $\mathrm{~N}$ & $\mathrm{~N}$ & $\mathrm{Y}$ & 88.3 & 0.16 & $\mathrm{n} / \mathrm{a}$ & 40 & 22.5 & $\begin{array}{l}\text { Random } \\
\text { Poisson }\end{array}$ \\
\hline \multicolumn{11}{|c|}{ Pittsburgh/Charleston database } \\
\hline 2011 & 32 & $\mathrm{~N}$ & $\mathrm{~N}$ & $\bar{Y}$ & 68.3 & 0.235 & $\mathrm{n} / \mathrm{a}$ & $20 ?$ & $\mathrm{n} / \mathrm{a}$ & Random \\
\hline
\end{tabular}

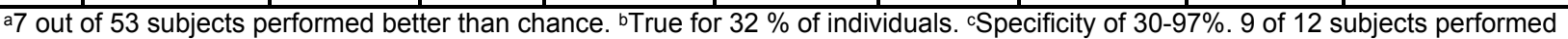
better than surrogates. ${ }^{d} 13$ out of 17 subjects performed better than chance. 7 out of 17 subjects performed better than chance. fonly area under (ROC) curve values of $0.5-0.93$ were reported. gPerfect performance found for each individual with at least one combination of feature and classifier. ${ }^{\mathrm{n} S p e c i f i c i t y ~ o f ~ 99.4-99.7 . ~ n / a, ~ n o t ~ a v a i l a b l e ; ~ R O C, ~ r e c e i v e r ~ o p e r a t i n g ~ c h a r a c t e r i s t i c . ~}$

1 Cook, M. J. et al. Prediction of seizure likelihood with a long-term, implanted seizure advisory system in patients with drug-resistant epilepsy: a first-in-man study. Lancet Neurol 12, 563-571 (2013).

2 Kiral-Kornek, I. et al. Epileptic seizure prediction using big data and deep learning: toward a mobile system. EBioMedicine 27, 103-111 (2018).

3 Karoly, P. et al. The Circadian Profile of Epilepsy Improves Seizure Forecasting. Brain 140, 2169-2182 (2017).

$4 \quad$ Kuhlmann, L. et al. Epilepsyecosystem.org: Crowd-Sourcing Reproducible Seizure Prediction with Long-Term Human Intracranial EEG. Brain In Press (2018).

5 Feldwisch-Drentrup, H. et al. Joining the benefits: combining epileptic seizure prediction methods. Epilepsia 51, 1598-1606 (2010).

6 Wang, S., Chaovalitwongse, W. A. \& Wong, S. Online seizure prediction using an adaptive learning approach. IEEE Trans. Know. Data Eng. 25, 2854-2866 (2013).

$7 \quad$ Xiao, C., Wang, S., lasemidis, L., Wong, S. \& Chaovalitwongse, W. A. An Adaptive Pattern Learning Framework to Personalize Online Seizure Prediction. IEEE Trans. Big Data, doi:10.1109/TBDATA.2017.2675982 (2017).

8 Sackellares, J. C. et al. Predictability analysis for an automated seizure prediction algorithm. J. Clin. Neurophysiol. 23, 509-520 (2006).

9 Kuhlmann, L. et al. Patient-specific bivariate-synchrony-based seizure prediction for short prediction horizons. Epilepsy Res. 91, 214-231 (2010).

10 Alvarado-Rojas, C. et al. Slow modulations of high-frequency activity $(40-140 \mathrm{~Hz})$ discriminate preictal changes in human focal epilepsy. Sci. Rep. 4 (2014).

11 Teixeira, C. A. et al. Epileptic seizure predictors based on computational intelligence techniques: A comparative study with 278 patients. Comput. Methods Programs Biomed. 114, 324-336 (2014).

12 Valderrama, M. et al. Identifying an increased risk of epileptic seizures using a multi-feature EEG-ECG classification. Biomed. Sig. Proc. Control 7, 237-244 (2012).

13 Rasekhi, J., Mollaei, M. R. K., Bandarabadi, M., Teixeira, C. A. \& Dourado, A. Epileptic seizure prediction based on ratio and differential linear univariate features. J. Med. Sig. Sens. 5, 1 (2015).

14 Rasekhi, J., Mollaei, M. R. K., Bandarabadi, M., Teixeira, C. A. \& Dourado, A. Preprocessing effects of 22 linear univariate features on the performance of seizure prediction methods. J. Neurosci. Methods 217, 9-16 (2013).

15 Bandarabadi, M., Teixeira, C. A., Rasekhi, J. \& Dourado, A. Epileptic seizure prediction using relative spectral power features. Clin. Neurophysiol. 126, 237-248 (2015).

16 Direito, B., Teixeira, C. A., Sales, F., Castelo-Branco, M. \& Dourado, A. A Realistic Seizure Prediction Study Based on Multiclass SVM. Int. J. Neural Syst. 27, 1750006 (2017).

17 Gadhoumi, K., Gotman, J. \& Lina, J. M. Scale invariance properties of intracerebral EEG improve seizure prediction in mesial temporal lobe epilepsy. PLoS One 10, e0121182 (2015).

18 Gadhoumi, K., Lina, J.-M. \& Gotman, J. Seizure prediction in patients with mesial temporal lobe epilepsy using EEG measures of state similarity. Clin. Neurophysiol. 124, 1745-1754 (2013). 
Senger, V. \& Tetzlaff, R. New Signal Processing Methods for the Development of Seizure Warning Devices in Epilepsy. IEEE Trans. Circuits Syst. I: Regular Papers 63, 609-616 (2016).

20 Zheng, Y., Wang, G., Li, K., Bao, G. \& Wang, J. Epileptic seizure prediction using phase synchronization based on bivariate empirical mode decomposition. Clin. Neurophysiol. 125, 1104-1111 (2014).

21 Aarabi, A. \& He, B. A rule-based seizure prediction method for focal neocortical epilepsy. Clin. Neurophysiol. 123, 1111-1122 (2012).

22 Park, Y., Luo, L., Parhi, K. K. \& Netoff, T. Seizure prediction with spectral power of EEG using cost sensitive support vector machines. Epilepsia 52, 1761-1770 (2011).

23 Williamson, J. R., Bliss, D. W., Browne, D. W. \& Narayanan, J. T. Seizure prediction using EEG spatiotemporal correlation structure. Epilepsy Behav. 25, 230-238 (2012).

24 Zhang, Z. \& Parhi, K. K. Low-Complexity Seizure Prediction From iEEG/sEEG Using Spectral Power and Ratios of Spectral Power. IEEE Trans. Biomed. Circ. Syst. 10, 693-706 (2015).

25 Mirowski, P., Madhavan, D., Lecun, Y. \& Kuzniecky, R. Classification of patterns of EEG synchronization for seizure prediction. Clin. Neurophysiol. 120, 1927-1940 (2009).

26 Moghim, N. \& Corne, D. W. Predicting epileptic seizures in advance. PloS one 9, e99334 (2014).

27 Eftekhar, A., Juffali, W., El-Imad, J., Constandinou, T. G. \& Toumazou, C. Ngram-derived pattern recognition for the detection and prediction of epileptic seizures. PloS one $\mathbf{9}$, e96235 (2014).

28 Aarabi, A. \& He, B. Seizure prediction in hippocampal and neocortical epilepsy using a model-based approach. Clin. Neurophysiol. 125, 930-940 (2014).

29 Li, S., Zhou, W., Yuan, Q. \& Liu, Y. Seizure prediction using spike rate of intracranial EEG. IEEE Trans. Neural Syst. Rehabil. Eng. 21, 880-886 (2013).

30 Zhang, Z. \& Parhi, K. K. in 37th Annual International Conference of the IEEE Engineering in Medicine and Biology Society (EMBC). (IEEE. p. 5748-5751).

31 Zandi, A. S., Tafreshi, R., Javidan, M. \& Dumont, G. A. Predicting epileptic seizures in scalp EEG based on a variational Bayesian Gaussian mixture model of zero-crossing intervals. IEEE Trans. Biomed. Eng. 60, 1401-1413 (2013).

32 Chien, J.-H. et al. A signal regularity-based automated seizure prediction algorithm using long-term scalp EEG recordings. Cybern. Syst. Anal. 47, 586-597 (2011). 